\title{
1 An Examination of an Enhanced Remote Sensing Method for Agent Attribution of \\ 2 Forest Disturbance
}

3

4 [bioRxiv]

5

6 Hugh Marshall Worsham ${ }^{1}$

$7 \quad{ }^{1}$ Energy and Resources Group, University of California, Berkeley

9 Corresponding:

10 Hugh Marshall Worsham

11310 Barrows Hall

12 University of California, Berkeley

13 Berkeley, CA 94720

14 United States

15 worsham@berkeley.edu

16 https://orcid.org/0000-0001-7924-040X 


\section{Abstract}

18 Patterns of disturbance in Sierra Nevada forests are shifting as a result of changing climate

19 and land uses. These changes have underscored the need for a monitoring system that both

20 detects disturbances and attributes them to different agents. Addressing this need will aid

21 forest management and conservation decision-making, potentially enhancing forests'

22 resilience to changing climatic conditions. In addition, it will advance understanding of the

23 patterns, drivers, and consequences of forest disturbance in space and time. This study

24 proposed and evaluated an enhanced method for disturbance agent attribution. Specifically,

25 it tested the extent to which textural information could improve the performance of an

26 ensemble learning method in predicting the agents of disturbance from remote sensing

27 observations. Random Forest (RF) models were developed to attribute disturbance to three

28 primary agents (fire, harvest, and drought) in Stanislaus National Forest, California,

29 U.S.A., between 1999 and 2015. To account for spectral behavior and topographical

30 characteristics that regulate vegetation and disturbance dynamics, the models were trained

31 on predictors derived from both the Landsat record and from a digital elevation model. The

32 predictors included measurements of spectral change acquired through temporal

33 segmentation of Landsat data; measurements of patch geometry; and a series of landscape

34 texture metrics. The texture metrics were generated using the Grey-Level Co-Occurrence

35 Matrix (GLCM). Two models were produced: one with GLCM texture metrics and one

36 without. The per-class and overall accuracies of each model were evaluated with out-of-bag

37 (OOB) observations and compared statistically to quantify the contribution of texture

38 metrics to classification skill. Overall OOB accuracy was $72.0 \%$ for the texture-free model

39 and $72.2 \%$ for the texture-dependent model, with no significant accuracy difference between

40 them. Spatial patterns in prediction maps cohered with expectations, with most harvest

41 concentrated in mid-elevation forests and fire and stress co-occurring at lower elevations. 
42 Altogether, the method yielded adequate identification of disturbance and moderate

43 attribution accuracy for multiple disturbance agents. While textures did not contribute

44 meaningfully to model skill, the study offers a strong foundation for future development,

45 which should focus on improving the efficacy of the model and generalizing it for systems

46 beyond the Central Sierra Nevada. 


\section{1. Introduction}

48 Disturbance regulates the composition and structure of temperate forests by altering

49 processes of vegetation growth, death, decomposition, and regeneration (Turner 2010).

50 Disturbance agents interact with pre-disturbance conditions to produce variable effects

51 with profound consequences for post-disturbance regeneration (Collins and Roller 2013,

52 Coop et al. 2016, Shive et al. 2018), as well as for carbon storage, water cycling, timber

53 productivity, wildlife habitat, and other ecological goods and services that forests provide.

54 Consider three examples. In the highest-intensity regions of a wildfire, living trees

55 of all age classes may be carbonized or left as standing or downed deadwood, while organic

56 material is consumed from the surface through much of the root zone (Cochrane and Ryan

57 2009, Perry et al. 2011). On the lower-intensity margins, fire may thin the understory or

58 selectively kill weakened individuals and more vulnerable species, freeing resources that

59 enable mid- to late-seral species to release (Braziunas et al. 2018). A clear-cut harvest, in

60 turn, abruptly removes most or all tree cover, leaving few or no standing stems (Franklin et

61 al. 2002, Tappeiner et al. 2015). Post-harvest regeneration must begin from "the ground

62 up," via an existing seedbank or artificial seeding or planting. On the other hand, some

63 forest disturbances are less abrupt. Mortality due to desiccation stress or beetle infestation

64 typically unfolds over months or years, often with species or age-class selectivity.

65 Infestations yield relatively slow declines in chlorophyll canopy content, frequently yielding

66 distinctive "red" and "gray" phases of decline, and standing dead stems may remain on site

67 for many years (Ciesla 2000). When salvage logging is not applied, much of the nutrient

68 stock may also be retained on site, as dead stems fall and decompose, but the site may face

69 an increased wildfire risk (Tappeiner et al. 2015, Larvie et al. 2018).

$70 \quad$ From a theoretical perspective, what constitutes a disturbance, and how

71 disturbances ought to be differentiated from other kinds or degrees of perturbation that 
72 affect biological communities, have proven thorny questions to answer (Sousa 1984).

73 Disturbances are often labeled "natural" (e.g., fire, windthrow, flood, pest infestation,

74 drought) or "anthropogenic" (e.g., biological invasion, forest management treatment,

75 fragmentation, roadcut, plantation-conversion) (Dale et al. 2001, Turner and Gardner

76 2015). However, insisting on a sharp line between these categories is unrealistic. In the

77 western United States, as in other parts of the world, the legacies of indigenous landscape

78 management practices likely cannot be disentangled from the region's "natural" fire regime

79 (Conedera et al. 2009, Trauernicht et al. 2015). Equally, anthropogenic climate change

80 appears to be influencing "natural" disturbance processes such as desiccation stress and

81 dieback in western U.S. forests (Clark et al. 2016).

82 Two further problems beset theoretical characterizations of disturbance. First,

83 without some qualification, the concept implies a possibility of stasis that rarely occurs in

84 natural systems (Connell and Sousa 1983, Sousa 1984). Many biological communities

85 readily shift among a set of alternative stable states (Beisner et al. 2003), or even

86 alternative transient states (Fukami and Nakajima 2011). In the absence of an objective

87 way to identify where a system lies within its alternative-state frontier at any moment, it is

88 hard to say when a perturbation is disruptive enough to qualify as a disturbance. Second,

89 disturbance agents often interact: to cite one example, drought stress can inhibit trees'

90 defenses against infections and parasites, in addition to rendering them more vulnerable to

91 fire. (Anderegg et al. 2015, Johnstone et al. 2016, Seidl and Rammer 2017, Simler et al.

92 2018). To attempt to differentiate particular agents as proximate or ultimate causes of

93 disturbance often seems more a hermeneutic exercise than an empirical one.

94 Considering these difficulties, while acknowledging that disturbance is nevertheless

95 a useful way to describe a class of environmental phenomenon, this paper holds with the

96 idea that disturbance "lies near one extreme of the continuum of perturbations that affect 
97 organisms" (Sousa 1984). It also assumes, sec. Peters et al. (2011), that an adequate

98 description of a given disturbance needs to account for at least: (1) the environmental

99 agent(s) of disturbance ("drivers"), (2) structural and functional characteristics of the

100 system prior to the disturbance (“initial system properties"), and (3) interactions between

101 the first two components that give rise to physical, chemical, and biological mechanisms of

102 change (“mechanisms"). An adequate description of disturbance should also consider the

103 consequences explicitly. The outcomes of forest disturbance can include vegetation

104 morbidity and mortality in the short-term and changes in age class, species composition

105 and dominance, hydrologic function, or ecosystem state (among others) in the long-term.

106 For this paper's purposes, I take forest disturbance to mean a discrete application of energy

107 to, or expenditure of energy within, a forested landscape that results in mortality,

108 morbidity, or displacement of vegetation and that opens opportunities for the establishment

109 of new individuals. I am primarily concerned with disturbances observable at the hectare

110 scale $\left(10,000 \mathrm{~m}^{2}\right)$ and larger, because of size of the area of study $\left(\sim 3600 \mathrm{~km}^{2}\right)$ and the spatial

111 resolution of the observations used $\left(\sim 900 \mathrm{~m}^{2}\right)$.

112

113 1.1. Forest disturbance and climate change

114 A growing body of evidence suggests that patterns of disturbance in the forests of

115 the Sierra Nevada of California are shifting (Breshears et al. 2005, Millar et al. 2007,

116 Adams et al. 2010, Allen et al. 2010, Cohen et al. 2016). For instance, timber harvesting in

117 national forests has decreased since the 1970s, while the incidence of wildfire and pest

118 infestation has increased (Oswalt et al. 2019). In the Sierra Nevada, desiccation stress was

119 widespread during the 2012-2015 drought, but it was also attended in some areas, such as

120 Sequoia \& Kings Canyon National Parks, by severe outbreaks of western and mountain

121 pine beetles (Larvie et al. 2018). 
So far, one consistent net effect of these shifts is high tree mortality (Potter 2017,

123 Crockett and Westerling 2018, Fettig et al. 2019). The new dynamics may also be inducing

124 species shifts and biodiversity losses (Paz-Kagan et al. 2017), and they could drive the

125 replacement of forests by non-forest land cover types, such as shrubland or meadow

126 (Thorne et al. 2017, 2018). Some have projected that these trends will continue as a result

127 of climate change and anthropogenic activity, with consequent impacts on the services that

128 currently forested landscapes provide.

129 Given these trends, advancing understanding of the patterns, drivers, and

130 consequences of forest disturbance in space and time is a research priority (Trumbore et al.

131 2015, Johnstone et al. 2016). McDowell et al. (2015) note a "lack of a comprehensive

132 monitoring system" that can both identify terrestrial disturbances and attribute them to

133 specific agents. Filling this gap would help forest resource managers understand how

134 forests respond to changing climatic conditions. In addition, reliable quantification of

135 historical and emerging disturbances will help to improve the skill of empirical models of

136 spatial pattern, population dynamics, forest regeneration, carbon storage, and water

137 cycling. In the long run, this effort could also improve the prospects for quantitative

138 description of ecological disturbance in the context of alternative stable (or transient) states

139 by improving the resolution of pre- and post-disturbance baselines. Finally, it will support

140 strategies for conserving, restoring, or adaptively transitioning forests in areas facing

141 increasing vulnerabilities to various agents of disturbance (Millar et al. 2007, Hansen and

142 Turner 2019).

144 1.2. Review of remote sensing methods for forest disturbance detection and attribution

145 Over the past decade, efforts to detect and attribute forest change have proliferated.

146 However, the field has yet to settle on a set of approaches that produce reliable estimates 
147 that can be compared across disturbance regimes or regions. The field currently comprises a

148 somewhat incongruent set of algorithms, satellite and aerial monitoring platforms, and

149 field assessment protocols. The USDA Forest Service's Forest Inventory and Analysis (FIA)

150 program provides data on most classes of forest-disturbance agent, but only across a

151 network of sampling plots (Schroeder et al. 2014). In California, the dataset extends back to

152 2001, with repeat surveys conducted on each plot approximately once a decade (Christensen

153 et al. 2016). This relative infrequency, along with the FIA's policy of obscuring the precise

154 locations of most sample plots, substantially limits the data's suitability for quantifying

155 spatially continuous change. Aerial insect and disease detection surveys are similarly

156 discontinuous and coarsely resolved in space and time. In response to these limitations,

157 researchers and managers have increasingly turned to satellite remote sensing methods for

158 their ability to capture a wide range of spatial and temporal variability across large regions.

159 The history of remote sensing methods for forest change detection extends at least

160 as far as the 1920s, when an entomology study analyzed oblique aerial photography to

161 identify spruce budworm mortality in Canadian spruce forests (Ciesla 2000). This process

162 was improved substantially by a double-sampling approach developed in the 1950s and

$1631960 \mathrm{~s}$, in which tree mortality estimates were made through stereoscopic interpretation of a

164 large sample of photographs and scaled up through statistical comparison with a smaller

165 sample of ground plots (Heller et al. 1959, Wear et al. 1966). Double sampling allowed for

166 statistically valid estimations of canopy loss across wide geographic areas (Lund 1997).

167 With the increasing availability of color and infrared film, researchers and forest managers

168 also began to exploit spectral information to identify crown fade and red and grey phases of

169 beetle infestations (Hadfield 1968, Hanson and Lautz 1971). With the launch of the first

170 civilian Earth-observing satellites, Landsat I in 1972, Geostationary Operational 
171 Environmental Satellite (GOES-1) in 1975, and the Advanced Very High Resolution

172 Radiometer (AVHRR) in 1978, remote sensing methods for forest change detection boomed.

173 Methods developed early on-and still in widespread use today-derive information

174 by comparing two or more images made at separate points in time over the same

175 geographic area. In pre-classification change detection methods, analysts compare the

176 images' raw spectral data. In post-classification techniques, each pixel in an image is

177 assigned to a defined land-cover type, and intertemporal differences are evaluated as

178 changes in class (Iverson et al. 1989). While post-classification approaches allow for the

179 integration of multiple data types and can minimize the effects of exogenous atmospheric or

180 radiometric distortions, they can carry an additional error burden due to information loss in

181 the classification procedure (Coops et al. 2007). More complex approaches in this category

182 involve principal component analysis, in which correlated spectral returns are compressed

183 so that change detection is performed on independent linear transformations of the original

184 data, and change vector analysis, which decomposes spectral responses into magnitude and

185 directional components (Fung and Ledrew 1987, Lu et al. 2004, Khorram et al. 2016). In

186 addition to uncovering dramatic vegetation changes around the world, these two-date

187 change-detection approaches identified two important requirements for any attempt at

188 forest change detection. First, special care must be taken to align the images geometrically

189 and radiometrically as nearly as possible to avoid false-negative change detection as a

190 result of registration inconsistencies. Second, it is imperative to account for seasonal

191 change, either through multi-band analysis, index computation, or seasonal compositing of

192 multiple images, as phenological change can easily be confused with stress-related change,

193 particularly in visible wavelengths (Khorram et al. 2016).

194 Because vegetation disturbance is a dynamic process operating on multiple

195 timescales, two-date comparison methods carry obvious limitations. In the mid-2000s, a 
196 suite of algorithms was developed to address this gap; these operate on the unique time

197 signatures that different directions and magnitudes of vegetation change leave behind

198 (García-Haro et al. 2001, Potter et al. 2007, Goodwin et al. 2008, Vogelmann et al. 2009,

199 2012). Such approaches are able to detect either abrupt changes (anomalies) or longer-

200 duration changes (trends) with suitable accuracy for monitoring and management. The

201 most sophisticated of these is the Vegetation Change Tracker (VCT) (Huang et al. 2010).

202 This method characterizes the temporal profile of each pixel in a time series stack and

203 classifies the pixels into one of several types (persistent forest, persistent non-forest,

204 disturbed forest, or regenerating forest), based on comparisons of absolute change in the

205 series with predetermined thresholds. Although these improve on two-date methods, as

206 Kennedy et al. (2010) point out, anomaly-targeted algorithms tend to exclude long-term

207 trend changes as noise, while trend-targeted algorithms do the same for abrupt anomalies.

208 Since 2010, a new generation of algorithms has emerged to disentangle remotely

209 sensed time series data to capture both abrupt disturbance events and longer-phase trend

210 change. These temporal segmentation algorithms are summarized in Table 1.

211 Although the methods differ somewhat in their implementation, in general they

212 apply a statistical model, such as linear segmentation, Fourier curve fitting, or quadratic

213 smoothing, to a time-series stack of remotely sensed data in order to derive information

214 about each pixel's spectral trajectory over time. The output is usually an array that

215 includes a per-pixel estimate of the location, timing, duration, and in some cases,

216 magnitude of spectral change. Based on these outputs, an analyst can inquire about

217 patterns of behavior among pixels or among aggregates formed based on the adjacency or

218 similarity of pixels in one or more dimensions.

219 In the U.S., researchers and managers have deployed both two-date image

220 differencing and the more complex algorithmic approaches in several prominent 
221 disturbance monitoring programs. Monitoring Trends in Burn Severity (MTBS) uses a two-

222 date procedure on Normalized Burn Ratio (NBR) values from Landsat images to map the

223 severity of large fires (Eidenshink et al. 2007). The ForWarn system uses Normalized

224 Difference Vegetation Index (NDVI) anomaly calculated on MODIS data to model

225 disturbances in near-real-time. However, its coarse spatial resolution (minimum $250 \mathrm{~m}$ )

226 makes it insensitive to finer-scale disturbances, including most management treatments on

227 public forested lands in the western U.S. (Hargrove et al. 2009). The LANDFIRE

228 disturbance database resolves 12 disturbance agent classes and dozens of sub-classes at 30-

229 m spatial resolution (Rollins 2009, Vogelmann et al. 2011). The program draws on multiple

230 algorithmic, remote sensing, and in situ data sources, including MTBS and VCT, but its

231 evidently incomplete record dates back only to 1999. The North American Forest Dynamics

232 program has leveraged the VCT algorithm to build a wall-to-wall map of U.S. forest

233 disturbance across the entire Landsat record at 30-m scale (Goward et al. 2016).

234 The efforts above have advanced detection of forest disturbance; methods for agent

235 attribution, on the other hand, remain embryonic. The most reliable approaches require

236 extensive technician analysis of multiple datastreams, including in situ observations,

237 management treatment records, and aerial- and satellite-platform sensing (e.g., Schmidt

238 2014, Cohen et al. 2016). The process is time-intensive and beset with error when multiple

239 forest types are under investigation, when multiple disturbance agents are active, and

240 when a site experiences more than one disturbance in the same period of analysis.

241 Automating this process through empirical modeling may help to reduce time and resource

242 requirements, in addition to improving accuracy of retrospective analyses and enhancing

243 the relevance of near-real-time disturbance detection and monitoring.

244 To date, a limited number of efforts at further automating agent attribution have

245 been published. The methods in this paper are heavily indebted to these projects. Neigh et 
246 al. (2014) used multiple indices derived from AVHRR and Landsat products in a decision-

247 tree classification to map insect kill and harvest in northern forests of Wisconsin and

248 Minnesota. They achieved per-class accuracy of $65-70 \%$ and overall accuracy of $72 \%$.

249 However, the same method applied to forests in the Pacific Northwest yielded inferior

250 results, indicating a need for further refinement before generalizing across forest types.

251 Kennedy et al. (2015) combined LandTrendr temporal segmentation of the 1984-2014

252 Landsat stack with a Random Forest classification approach (Breiman 2001) to map

253 multiple agent classes in the Pacific Northwest. Oeser and colleagues (2017) applied a

254 similar approach in Central European temperate forests, applying BFAST temporal

255 segmentation to identify abrupt forest loss and passing the resulting spatio-temporal

256 information into a Random Forest classification. They identified harvest, windthrow,

257 cleared windthrow, and bark beetles to 76-86\% accuracy. Schroeder et al. (2017) classified

258 fire, harvest, conversion, wind, and drought stress with a Random Forest model trained on

259 VCT and ancillary geophysical variables. Their approach yielded high accuracy (69-86\%)

260 across ten Landsat scenes made over various ecoregions of the United States. Interestingly,

261 accuracy was higher when information about the timing (year) of disturbance was excluded

262 from the model. Shimizu et al. (2017) also used Random Forest to classify patches of

263 contemporaneously disturbed pixels to discriminate anthropogenic forest changes, such as

264 logging, plantation conversion, and urbanization in Myanmar. Finally, Shimizu et al. (2019)

265 evaluated the relative effectiveness of several different approaches to disturbance-agent

266 classification in a South Asian tropical forest: threshold-based detection using one spectral

267 index, machine-learning methods trained on temporally segmented vegetation index values,

268 and one machine-learning method trained directly on the Landsat time series without prior

269 temporal segmentation. They found that direct prediction performed better than

270 approaches that included temporal segmentation, with considerable savings in complexity 
271 and computational expenditure, but it remains to be seen whether this approach works as

272 well as two-stage methods in other forest types.

273 Clearly, there is enthusiasm for solving the agent-attribution problem, and the early

274 work suggests that remotely sensed information shows promise for resolving different types

275 of forest disturbance into distinct classes. But much remains to be done to achieve a

276 generalizable method. Some key areas for development include:

277

278

279

280

281

282

283

284

285

286

287

288 Here, I address the last two of these prompts by making novel use of NIR $\mathrm{V}$ and by testing

289 the contribution of textural information to agent-attribution accuracy.

(1) identifying the most effective combination of spectral bands and indices for accurate modeling across landscape types;

(2) determining whether a two-stage method (temporal segmentation plus classification) or a one-stage method (direct classification without temporal segmentation) consistently yields higher accuracy;

(3) making use of new spectral measurements of solar-induced chlorophyll fluorescence (SIF), such as the NASA Orbiting Carbon Observatories' (OCO-2 and OCO-3) SIF products and the Near-Infrared Reflectance of Vegetation (NIRv) index; and

(4) assessing whether textural information derived from Landsat scenes can improve classification results.

291 1.3. $\quad N I R_{V}$

293 directly measures the fraction of near-infrared reflectance attributable to chlorophyll,

294 yielding accurate estimates of photosynthesis rate and gross primary production (GPP)

295 (Badgley et al. 2017, 2019, Wu et al. 2020). NIR $\mathrm{V}$ tends to be more sensitive to decreases in 
296 photosynthetic capacity than other vegetation indices, which offers reason to think that a

297 model trained on NIRv may improve detection of sublethal phases of stress-related

298 disturbances (e.g., drought, beetle infestation).

\subsection{Texture}

$301 \quad$ On texture, as this paper's introduction describes, different agents and intensities of

302 disturbance leave different structural legacies on forested landscapes. Vegetation structure,

303 in turn, has been shown to resolve well in textural patterns derived from optical remote

304 sensing measurements (Wood et al. 2012, Lam et al. 2013). At the most basic level, texture

305 describes certain spatial properties of a surface-in ordinary experience, these include

306 properties such as smoothness, coarseness, or sharpness. Quantifying texture for analytic

307 purposes is a matter of measuring and expressing differences between high and low points

308 on a surface ( $z$ differences in Cartesian space), and how near or far those points are from

309 one another ( $x-y$ differences). Smoother surfaces tend to have smaller $x-y-z$ differences,

310 while rougher surfaces tend to have larger differences. Smoothness and coarseness are only

311 two of many relevant textural properties that can be measured statistically from images of

312 a surface. One widely deployed set of metrics is that derived from the Gray Level Co-

313 occurrence Matrix (GLCM) (Haralick et al. 1973). The GLCM procedure tabulates the

314 frequency of co-occurrence of pixel brightness values in adjacent pixels using a set of

315 moving-window comparisons. These frequencies are then used to compute a set of $14+$

316 distinct measurements of texture.

317 At the pixel level, GLCM metrics describe second-order statistical properties. First-

318 order information, such as the spectral reflectance intercepted by a sensor and recorded as

319 pixel values, generally measures physical behavior (reflectance of electromagnetic energy)

320 or chemical activity (photosynthesis) or a statistically verifiable proxy for the same. GLCM, 
321 on the other hand, quantifies relationships between pairs of pixels (Hall-Beyer 2017). First-

322 and second-order metrics tend to be statistically independent of each other and so can

323 contribute complementary information to landscape analyses. GLCM textures have long

324 been applied in combination with other variables to improve accuracy of land-use and land-

325 cover classification (Coburn and Roberts 2004). The applicability of GLCM metrics for forest

326 structure analysis has been demonstrated using both high-resolution (IKONOS) and

327 moderate-resolution (SPOT, Sentinel-1, ASTER, Landsat) data, though it likely has much

328 lower utility in land cover applications at spatial resolutions lower than $\sim 50 \mathrm{~m}$ per pixel

329 (Marceau et al. 1990, Ozdemir et al. 2012, Wood et al. 2012).

330 Textural metrics have the potential to improve disturbance agent attribution

331 because of the relationships between agent and stand structure on the ground, and between

332 stand structure and texture in images. These relationships may be especially important in

333 the Central Sierra Nevada forests evaluated in this study because of the agents that are

334 most prevalent in the region: fire, drought, insects, and harvest. These tend to leave

335 visually distinctive and analytically differentiable patterns on the landscape (Fig. 1) and

336 may contribute decision-enhancing information to an agent-attribution modeling procedure.

338 1.5. Motivation

339 California's Central Sierra Nevada offers valuable opportunities to study forest

340 disturbance and its drivers using the emerging remote sensing methods described above.

341 Observed climatic changes, including warmer winter and spring temperatures,

342 precipitation shifts from snow to rain, lower peak snowpack depth, and early spring

343 drydown, have been documented across the region (Vicuna and Dracup 2007). These shifts

344 are connected to a multitude of forest changes. For example, whitebark pine (Pinus

345 albicaulis Engelm.) and ponderosa pine (Pinus ponderosa) have experienced widespread 
346 mortality due to mountain pine beetle, western pine beetle, and desiccation stress (Millar et

347 al. 2012, Birdsey et al. 2019). The region has also faced compositional shifts and increases

348 in stem density in mid-elevation coniferous stands, as well as canyon oak regeneration in

349 stands previously occupied by conifers (Dolanc et al. 2013, 2014).

350 The site selected for study, Stanislaus National Forest, is an archetype of these

351 trends. Fire, harvest, thinning, drought, and insect stress have been extensive and well

352 distributed across elevational gradients over the past three decades. The prevalence of

353 disturbance makes it a prime site for an attempt at complex disturbance agent attribution.

354 Indeed, the Forest has been a subject of at least two prior disturbance-detection studies

355 using LandTrendr and VCT, respectively (Schmidt 2014, Birdsey et al. 2019). Both relied on

356 manual interpretation of multiple data sources for agent attribution. Schroeder et al.'s

357 (2017) semi-automated approach using VCT and Random Forest classification included one

358 Landsat tile that partially overlapped the Forest. Their results showed agent classification

359 agreement above 90 percent for the Sierra Nevada site, indicating strong potential for this

360 approach in the region.

361 The overarching aim of this project was to test whether a Random Forest ensemble

362 learning method for classifying forest disturbance agents at the 30-m Landsat pixel scale

363 can be improved by incorporating textural information.

364

365 1.6. Research questions

366 1. To what extent does the inclusion of textural information improve attribution of the 367 agents of disturbance in Stanislaus National Forest?

3692 . What are the relative contributions of three independent textural metrics to $370 \quad$ classification accuracy? 


\section{$372 \quad$ 1.7. Study objectives}

373 1. $\quad$ Agent-attribution model: Evaluate the capacity of an ensemble learning method to classify Landsat-derived pixel data according to three agent-based forest

2. Texture contribution to accuracy: Assess the per-class and overall accuracy of texture-free and texture-dependent agent models to evaluate whether a model with textural metrics is more effective at identifying agents of disturbance than one without.

3. Variable importance: Determine which predictor variables are most useful for

\section{Methods}

385 2.1. Study site

387 USDA Forest Service on the western slope of the Sierra Nevada in California (Fig. 2). The

388 forest abuts the northern border of Yosemite National Park and contains three federal

389 Wilderness areas (Mokelumne, Carson-Iceberg, and Emigrant) to the north and east. The

390 region's climate is Mediterranean, with average precipitation around $125 \mathrm{~cm}(990 \mathrm{~cm}$

391 equivalent snowfall.) The jurisdiction spans a broad elevational gradient, from $450 \mathrm{~m}$ in the

392 western foothills to over 3350 m near the Sierra crest. The Forest contains more than 1200

$393 \mathrm{~km}$ of rivers and streams. Vegetative communities include oak woodlands at lower

394 elevations, mixed conifer forests at middle elevations, and subalpine vegetative

395 communities at the highest elevations. 
Since 2000, the Forest has experienced two major wildfires: the 2013-2014 Rim Fire,

397 which burned 257,314 acres and the 2018 Donnell Fire, which burned 36,450 acres. Forest

398 ecosystems in the domain are subject to other natural disturbance regimes, such as conifer

399 beetle eruptions, severe winter wind events, and avalanches. They are also harvested for

400 merchantable timber and thinned for fire resistance, pest management, species selection,

401 and site productivity; these operations often register as vegetation loss in change-detection

402 analyses, but because of forest management practice guidelines, are typically constrained to

403 clearly delineated areas less than 16 hectares $\left(0.16 \mathrm{~km}^{2}\right)$.

405 2.2. Data preparation

406 2.2.1. Reference data

407 Ideally, reference data for model training and accuracy assessment would come from

408 data acquired in the field. However, a consistent, spatially explicit longitudinal record of in

409 situ disturbance observations does not exist for California, and due to time and cost

410 constraints I was unable to assemble such a record myself. Instead, I used the Landscape

411 Fire and Resource Management Planning Tools (LANDFIRE) Disturbance Public Model-

412 Ready Events Geodatabase. In its original form, this dataset comprises a set of polygon

413 shapefiles demarking the locations, extents, types, and timing of disturbances and

414 management treatments. The polygons are submitted annually to LANDFIRE, a joint

415 program of the USDA Forest Service and U.S. Department of the Interior, by contributors

416 from federal and state resource management agencies, private organizations, and

417 national/regional fire mapping programs, such as MTBS and CalFire's Fire and Resource

418 Assessment Program (FRAP). Data submissions must meet minimum standards for

419 inclusion, and they are subsequently analyzed for positional accuracy and quality and then

420 corrected for topological inconsistencies. In the Model Ready Events dataset, the set of 
421 polygons is reduced to portray one unique event per location per year between 1999 and

422 2014, using a hierarchical decision procedure. The polygons that comprise the final dataset

423 are those with the greatest-magnitude impact on vegetation.

Because these data were used for training as well as validation, the model inherits

425 error from the reference set. However, LANDFIRE currently offers the most extensive and

426 longest record of disturbances and treatments available for the study area. (The dataset

427 also offers nearly full coverage of the continental United States, which would aid testing of

428 the generalizability of the methods in this study in the future). Moreover, with the

429 exception of data generated by MTBS, the records are created without reliance on Landsat

430 observations. In the study area, because of the extensive records maintained by CalFire

431 FRAP, none of the fire event polygons were derived from MTBS. It stands to reason that

432 the reference set is as independent of the predictor data as is feasible. I considered the

433 reference set sufficient in light of the fact that this is foremost a proof-of-concept study but

434 acknowledge that more reliable training and reference data would improve the reliability of

435 the model.

436 I converted the polygons to Geotiff raster format and randomly selected 200 sample

437 points from each of five strata: fire, harvest/treatment, stress, stable forest, and stable non-

438 forest. For each of the disturbed points, I preserved the year reported and the assigned

439 disturbance agent from LANDFIRE. In some cases, the sampling yielded multiple

440 disturbances per point during the time interval. When this happened, I selected the

441 highest-severity disturbance in the set to maintain consistency with the procedure in the

442 temporal-segmentation algorithm described in $\$ 2.2 .2$ below. The 1000 total sample points

443 represented three classes of disturbance agent (fire, harvest, stress) and two classes of

444 stability (stable forest, stable non-forest). 
A flowchart of the remaining analytical steps appears in Fig. 3. The next task was to

448 generate predictor variables for training the classification model. Using the Google Earth

449 Engine API (Gorelick et al. 2017), I assembled an image collection of Landsat 5 Thematic

450 Mapper (TM), Landsat 7 Enhanced Thematic Mapper (ETM+) and Landsat 8 Operational

451 Land Imager (OLI) datasets acquired over the study area, preprocessed to Tier 1 surface

452 reflectance. ETM+ and OLI data provide moderate-to-high spatial and temporal resolution

453 (30 meters per pixel for non-thermal bands on a 16-day return interval). They offer

454 adequate spectral resolution for vegetation change detection.

455 The image collection included all images made during the peak growing season

456 (June 21 - September 20) in the years between 1999 and 2015, inclusive. Next, to

457 standardize the ETM+ and OLI data, I applied a slope-intercept harmonization algorithm,

458 which normalized OLI surface reflectance values to ETM+ values. A detailed discussion of

459 this procedure is available in Roy et al. (2016). I then applied a masking function to each

460 image using the pixel-QA band to remove clouds, snow, cloud shadows, and water, in order

461 to avoid generating outlier band ratio values that could lead to false positive change

462 detection. The final collection contained 373 images in total, between nine and 31 per year

463 for an average of 22 images per year.

464 The next step was to build a summary dataset of annual surface reflectance images.

465 I computed the medoid value per pixel from the annual subsets of masked image

466 collections. The medoid is a measure of center that minimizes the vector distance to all

467 other points in the set. In an odd set in one-dimensional number space, this is the median.

468 In an even set, in which the median would fall in the interval between two values, the

469 medoid is constrained to one of the values actually present in the dataset. In this case, the 
470 medoid computation selected the lower value in the interval. Medoid compositing produced

47117 images, one for each year in the study period.

472 The consequence of this compositing was that subsequent analysis evaluated

473 interannual change, a significant scaling up from the 16-day temporal resolution of the

474 original Landsat data. There are tradeoffs in any data selection procedure. While some

475 information is compressed or lost in generating annual medoids, this process reduces the

476 error in intertemporal comparison resulting from radiometric differences between images

477 made at different times of day and year. It also helps to moderate phenological variance

478 and spectral errors thrown by late snowpack or early snowfall. The aim is to produce a

479 relatively consistent set of images for comparison, while preserving strong signals of

480 change. Because disturbance legacies usually remain detectable on a forested landscape for

481 several years after the event (except when salvage harvest is applied), annual compositing

482 tends to improve the accuracy of disturbance detection on net (Kennedy et al. 2010).

483 Finally, I computed three vegetation indices on the medoid spectral values as inputs

484 to the temporal segmentation procedure $(\$ 2.2 .3)$. Dozens of spectral indices have been

485 proposed for distinguishing vegetation from other forms of land cover (Khorram et al. 2016).

486 All require computations, typically on combinations of visible and infrared bands, that

487 amplify the spectral signal of vegetative cover and diminish the signal of non-vegetative

488 cover. Several indices have been found especially useful in identifying disturbance (Miller

489 et al. 2009, Neigh et al. 2014b, Potter 2014, McDowell et al. 2015, Senf et al. 2015, Cohen et

490 al. 2018). The two most often used are the Normalized Difference Vegetation Index (NDVI)

491 (Rouse et al. 1974) and Normalized Burn Ratio (NBR) (Keeley 2009). However, recent

492 studies have concluded that a combination of spectral indices enhances disturbance

493 detection accuracy, likely because no one index fully captures the spectral behavior of a 
494 landscape in flux. Therefore, in keeping with recent trends toward multi-index

495 classification, I included three indices: NDVI, NBR, and NIRv (Table 2).

496 For each index, I scaled the results by $10^{3}$ to allow the temporal segmentation

497 algorithm to operate on integer values without losing precision and then inverted the

498 values so that negative index change would correspond with vegetation loss.

\subsubsection{Disturbance detection through temporal segmentation}

The final post-processed index images were used to produce a suite of derivative

502 change variables, which were later applied as predictors in the agent-attribution

503 classification model.

504 LandTrendr (Kennedy et al. 2010, 2018) is one of several algorithms available for

505 temporal segmentation of time series data. The core of the algorithm is an attempt to create

506 fitted models of pixels' spectral behavior. When configured appropriately for the image set,

507 this process strikes a balance between removing "noisy" interannual variability while

508 identifying the maximum possible number of significant changes in the pixel's record.

509 Operating sequentially on each pixel in the stack of annual medoids, the algorithm returns

510 a series of straight-line segments joined at vertices where the change in spectral value is

511 significant enough to be considered an inflection point. The algorithm iteratively generates

512 simpler models and then selects the model that best fits the original data.

513 The Google Earth Engine implementation of the LandTrendr algorithm (Kennedy et

514 al. 2018) was run over each of the three vegetation index collections. The codebase accepts

515 several user-defined inputs. I constrained the analysis to starting values of NDVI > 120,

516 NBR $>170$, and $\mathrm{NIR}_{\mathrm{V}}>210$. This trimming filtered out values that began below standard

517 thresholds for vegetation on each index and persisted through the time series as stable non-

518 forest. I also constrained the analysis to compute a maximum of 12 segments. I considered 
519 any change that did not persist for at least one year beyond the initial detection to be

520 erroneous. (Fast spectral recoveries in forest remote sensing data are more often a result of

521 radiometric noise or insufficient cloud/shadow masking than of vegetation vigor (Kennedy

522 et al. 2010)). I therefore removed vertices where an apparent change returned to starting

523 value within two years. For fitted model selection, I specified two best-fit criteria: the

524 algorithm must select the model with the most vertices (again, to detect all changes in the

525 record), but it must have a p-value within 0.75 of the model with the absolute lowest $\mathrm{p}$.

526 Illustrations of the model fitting results appear in Fig. 4, which depicts the spectral

527 behavior of three randomly selected pixels identified, respectively, as "Disturbed", "Stable

528 Forest", and "Stable Non-Forest" through the temporal segmentation procedure. In this

529 example, the algorithm simplified the shape of the "Disturbed" pixel's trajectory from 17

530 segments in the original $\mathrm{NIR}_{\mathrm{V}}$ returns to 5 in the best-fit model. The fitted model detected

531 three disturbance events (in 2000, 2001, and 2009), followed by a period of regeneration.

532 The largest magnitude disturbance occurred between 2000 and $2001\left(\Delta \mathrm{NIR}_{\mathrm{V}}=200\right)$, with a

533 duration of one year and a rate of 200/1 = 200. The "Stable Forest" pixel's trajectory was

534 reduced to one segment with $\Delta \mathrm{NIR}_{\mathrm{V}}=0$. The "Stable Non-Forest" trajectory was simplified

535 to two segments. Its absolute $\mathrm{NIR}_{\mathrm{V}}$ values never exceeded the threshold for consideration as

536 vegetation $\left(\mathrm{NIR}_{\mathrm{V}}=210\right)$, so the pixel was considered undisturbed.

537 After finding the best segment fits, several metrics derived from the trajectories

538 were computed on each pixel, summarized in Table 3. The five-dimensional arrays

539 containing these values were sliced to include only segments representing negative change

540 greater than 10 percent, in order to remove periods of stability, periods of vegetation

541 growth, and low-value outliers. (I make no further inferences about the excluded segments.)

542 This process operationalized the concept of disturbance as any negative change in the

543 vegetation index of a pixel greater than 10 percent. I selected the greatest-magnitude 
544 segment for each pixel. Multidimensional analysis would have exceeded the capacity of the

545 computing resources I have available, and the greatest-magnitude disturbance on a site

546 typically has the greatest influence on forest structure and regeneration dynamics. Finally,

547 I cropped the arrays containing these outputs to a multipolygon shapefile delimiting the

548 boundaries of Stanislaus National Forest (USDA Forest Service 2019).

550 2.2.4. Derived variables

$551 \quad$ From these outputs, several derivative variables were calculated on each pixel and

552 on pixel clusters. First, land-cover ternary maps were produced by labeling pixels according

553 to the three possible trajectory groups identified the temporal segmentation procedure.

554 Pixels with a detected negative change were labeled "disturbed"; undisturbed pixels with

555 values persistently above the index vegetation thresholds were labeled "stable forest"; and

556 undisturbed pixels with values persistently below the index vegetation thresholds as

557 "stable non-forest." One ternary map was created for the temporal segmentation results for

558 each vegetation index, for a total of three maps.

559 Next, texture metrics were computed to quantify the textural characteristics of

560 different disturbance classes. Using the "glcmTexture" function in Google Earth Engine

561 (Gorelick et al. 2017), I calculated 14 GLCM metrics on each of the vegetation index images

562 (3 indices x 17 years x 14 metrics $=294$ GLCM metrics). GLCM proceeds by tallying the

563 frequency of occurrence of pairs of pixel brightness ("grey-level”) values in a user-defined

564 neighborhood. The frequencies are normalized to the number of observations to produce

565 probabilities (Hall-Beyer 2017). These probabilities are then applied in a series of

566 calculations whose results may be roughly categorized as "edge" metrics and "interior"

567 metrics. Edge metrics produce higher values for larger and more abrupt differences in 
568 brightness values in the computing neighborhood. Interior metrics produce higher values

569 for smaller and more heterogeneous gradients in brightness values.

570 Of course, edge and interior are highly scale-dependent qualities of an image, as of a

571 landscape. In a high-resolution image of a forest, a tree crown might be discernable as an

572 edge, while its constituent branches and leaves compose the interior; in a moderate-

573 resolution image, only the edges of patches might be discernable, and multiple trees then

574 make up the interior. It is important, therefore, to identify an appropriate scale for GLCM

575 computation. Owing to the native resolution of Landsat source data and the focus on

576 disturbance at the hectare scale or greater, I used a square 3x3 pixel window to define the

577 computing neighborhood, so that each pixel was compared with its eight edge- and corner-

578 adjacent neighbors in the frequency calculations. This produced texture measurements at

579 the approximately one-hectare patch scale.

580 GLCM produces 14 distinct metrics, but many of them are correlated. Including

581 them all in a classification model would produce redundancies that could reduce model skill

582 and/or distort the evaluation of variable explanatory power (Kim et al. 2009). Based on

583 guidance in Hall-Beyer (2017), I identified three theoretically independent measures to

584 apply in the final analysis (Table 4).

585 Contrast measures the intensity contrast between neighboring pixels and tends to be

586 a reliable edge metric in vegetated landscapes (Hall-Beyer 2017). Entropy is also often a

587 fruitful edge metric, particularly in areas with a high heterogeneity of radiometric

588 intensities, as in disturbed forest with deadfall, and it may be useful for differentiating

589 structural randomness from more uniform structures (Haralick et al. 1973). Correlation is

590 an interior metric that captures the prevalence or absence of linear structure. After

591 computing the texture metrics, I masked out undisturbed pixels and recoded them to a

592 discrete NA value outside the $\mathrm{NIR}_{\mathrm{V}}$ range. 
594 paired separately. The Pearson correlation coefficient ( $r$ ) was computed on all pairs and

595 reported in a correlation matrix. The three proposed measures were confirmed for inclusion

596 only if they were uncorrelated or weakly correlated (either $p>0.01$ or $r<0.3$ for significant

597 correlations).

598 Next, in order to exploit the variability in geometric patterns associated with

599 different disturbance classes, I used a 3x3 moving window segmentation algorithm to group

600 pixels disturbed in each year into disturbed patches. I then calculated the perimeter, area,

601 and fractal dimension of each patch. Fractal dimension is effectively an enhanced

602 perimeter:area ratio, normalized to the expected ratio of a square and then scaled

603 logarithmically to reduce the metric's size dependence $(\ln (0.25 *$ perimeter $) / \ln ($ area $))$

604 (Turner and Gardner 2015).

605

606 


\subsubsection{Ancillary topographical data}

608 The final step in data preparation was to generate geophysical variables to account

609 for topographical regulation of forest occurrence and disturbance dynamics. The National

610 Elevation Dataset Digital Elevation Model (DEM) was resampled to 30-m pixel resolution.

611 Slope, elevation, sine-transformed aspect and cosine-transformed aspect were computed

612 and draped over the study site (Beers et al. 1966; Schroeder et al. 2017).

613

614 2.3. Random Forest classification model

615 A Random Forest (RF) procedure (Breiman 2001) was used to empirically model the

616 occurrence of the four classes of disturbance identified in the reference dataset (fire,

617 harvest, stress, conversion) and stable forest. RF is a non-parametric modeling framework

618 that takes randomized bootstrap samples of subsets of predictor and response variables and

619 uses them to construct an ensemble of many slightly different decision trees. When RF is

620 used for image classification with a categorical response variable, the end-nodes of these

621 trees comprise a set of potential classification decisions for each pixel. The procedure makes

622 a final prediction about the correct class through a majority vote. RF was selected on three

623 criteria. First was its ability to assimilate potentially highly correlated datastreams

624 without overfitting and, owing to the majority-vote procedure, with only minor bias

625 concessions. Second was its value-indifference: because the classification ultimately

626 depends on decision trees, a variable's relative value rather than its absolute magnitude

627 drives the training decision. Incorporating data of widely different magnitudes does not

628 therefore force model decisions toward predictors with higher absolute values. And third

629 was its nearly exclusive use in other disturbance agent-attribution modeling approaches.

630 Two models were developed in R (R Core Team 2014) using the "ModelMap" package

631 (Freeman et al. 2016), which optimizes ensemble modeling procedures for geospatial 
632 analysis. The first model was produced without textural variables and the second with

633 textural variables included. In both instances, I used the 1000 points sampled from the

634 reference dataset as trainers, with 200 points in each class. In the first model, 22 predictor

635 variables were used; in the second model, 31 variables were used (Appendix B). The

636 predictor sets contained true pixel values for the entire domain in the topographic and

637 ternary variables. The remaining variables contained true values only for disturbed pixels.

638 In these cases, the non-disturbed pixels received a discrete NA value outside their true

639 ranges.

640 In early tuning of the models, different numbers of independent trees $(101,201,501$,

641 1001, and 2001) were tested incrementally. The number of trees required to stabilize

642 accuracy and variable importance (i.e., the point where increases in the number of trees did

643 not affect overall accuracy or predictor importance rank) fell between 201 and 501 . The

644 final models were set to assemble 501 trees. (The extra unit was included to break voting

645 ties). Eight predictor variables were used per bootstrap run to decide on node splits. This

646 was based on guidance in Freeman et al. (2016) to begin with a sample size equal to one-

647 third the number of variables, and then to test increments above and below that number.

648 Accuracy stabilized when eight variables were selected, so the final models were set to

649 sample eight variables.

650 The predictors were randomly sampled in the construction of each tree, and all of

651 the predictors were ultimately used. Maps of disturbance agent predictions at pixel level

652 were produced in ModelMap.

653

654 


\subsection{Accuracy assessment and variable importance}

Accuracy was assessed at three separate stages. First, the accuracy of disturbance

657 detection in the temporal segmentation procedure (\$2.2.3) was evaluated against a testing

658 set (\$2.2.1). The reference image was reduced by collapsing fire, harvest, and stress into a

659 single "disturbed" cover class; in the resulting image, all pixels were assigned to one of

660 three categorical values: stable forest, stable non-forest, and disturbed. A testing set was

661 created via stratified random sampling of this image, excluding pixels that had been used

662 in model training. The testing points were interpreted in the same manner as the training

663 data. The procedure yielded 200 points per class, for a total of 600 testing points. These

664 points were then used as the basis for comparison with the three cover ternary images

665 (\$2.2.4). Omission and commission errors were calculated for disturbed, stable forest, and

666 unstable forest, along with overall agreement scores and Cohen's Kappa ( $\kappa$ ) statistics for

667 each vegetation index. $\kappa$ is a multivariate measure of accuracy that accounts for the

668 possibility of agreement by chance. The coefficient is calculated from the error matrix and

669 ranges from zero to one, with zero representing random-chance agreement and one

670 representing perfect agreement. In land-cover classification, generally accepted targets for

671 each of these metrics are overall accuracy $>85 \%$, per-class accuracy $>70 \%$, and $\kappa>0.61$

672 (Foody 2002).

673 Second, the accuracy of disturbance detection in the RF models (\$2.3) was evaluated

674 against the testing set to quantify any gross information gain or loss that might have been

675 produced in the RF. In this case, the RF maps were converted to raster format and overlaid

676 on the ternary reference image to form a multi-band raster. The same testing points were

677 extracted, and the same bundle of accuracy metrics was produced.

678 Third, the accuracy of disturbance agent-attribution was assessed using out-of-bag

679 (OOB) estimates. OOB reports the mean prediction error for each training sample, 
680 calculated on the trees that were excluded from the bootstrap sampling operation. Because

681 OOB observations are excluded from model training, they are thought to offer reliable

682 accuracy estimates. Omission and commission errors, overall agreement, and $\kappa$ statistics

683 were measured for both RF models.

684 Mean decrease in accuracy (MDA) was used to evaluate the relative importance of

685 predictors in the two models. Interpreting the absolute importance of individual predictors

686 presents challenges in RF models because the procedure reduces hundreds of intermediate

687 decisions to a single per-pixel vote. MDA, however, enables comparisons of relative variable

688 importance across trees. The statistic measures how much predictive power would be lost

689 (i.e., the percent increase in predictive error that would arise) if a variable were removed

690 from the model. MDA values were computed and ranked for both models. Accuracy and

691 MDA statistics were compared to evaluate the contribution of textural information to model

692 skill.

693

694 3. Results

695

696 3.1. Texture metric correlations

697 Correlation testing was performed on the set of 13 GLCM texture metrics to validate

698 the assumption that contrast, correlation, and entropy were weakly correlated and

699 therefore contributed independent streams of information to the model. Each GLCM metric

700 was paired separately with the other 13 in the set, and the correlation coefficient Pearson's

$701 \quad r$ was computed for each pair. Graphical representations of these correlations appear in Fig.

7025 . As expected, several of the texture metrics were closely correlated, as indicated by

703 narrower ellipses and more-saturated colors. For instance, contrast and variance-two

704 "edge" measures—were well correlated in the data (Pearson's $r=0.975 ; \mathrm{p}<0.01$ ). This 
705 tends to be the case when a landscape has very clearly defined edges. Where highly

706 correlated variable pairs are thought to measure similar properties of a landscape, it is

707 prudent to select only one member of the pair in order to develop a statistically independent

708 metric set.

709 The three proposed texture metrics-contrast, correlation, and entropy-were

710 sufficiently weakly correlated to be confirmed for inclusion as textural predictors (Pearson's

$711 r<0.3)$ (Table 5). Spatially explicit depictions of these metrics calculated on NIRv returns

712 from 2014 are depicted in Fig. 6 for a $25 \mathrm{~km}^{2}$ subset of the study domain.

713 The reason for selecting independent (or weakly correlated) texture metrics has to do

714 with how RF handles variable importance for highly correlated predictors (Schroeder et al.

715 2014, Freeman et al. 2015). One of the advantages of RF is that it can assimilate correlated

716 variables without sacrificing accuracy or overfitting to the data. A tradeoff, however, is that

717 it tends to spread out importance across those correlated variables, which makes assessing

718 relative variable importance difficult. For the purposes of overall model accuracy, this is not

719 such a problem. But since this study is explicitly testing the importance and contribution of

720 distinct texture metrics, it was necessary, to the extent possible, to use independent

721 measures.

723 3.2. Disturbance detection: temporal segmentation of vegetation index time series

724 The percentage of pixels identified as disturbed in the study area each year ranged

725 widely, from $0.20 \%$ in 2011 to $15.6 \%$ in 2014 (Fig. 7). The three vegetation indices yielded

726 similar patterns of detection, with $\mathrm{NIR}_{\mathrm{V}}$ yielding the greatest total number of disturbed

727 pixels across all years $\left(1.45 \times 10^{6}\right)$ and NDVI the fewest $\left(1.36 \times 10^{6}\right)$.

728 The first accuracy assessment was also conducted at this stage. Overall accuracy of

729 disturbance detection through temporal segmentation of NBR, NDVI, and NIRV time-series 
730 stacks ranged from $69.3 \%$ to $74.2 \%$ (Table 6). All accuracy results were significantly better

731 than random $(\mathrm{p}<0.01)$, and there was no significant difference in accuracy among the three

732 indices $(\mathrm{p}>0.01)$.

733 To enable comparisons among NDVI, NBR, and NIRv, their magnitude values were

734 re-normalized to a $0-1$ scale. $\mathrm{RF}$ is generally scale-indifferent, but normalizing is useful

735 for comparing mapped values. Histograms and map renderings in Fig. 8 depict the

736 distribution of normalized magnitudes. NDVI and NBR were similarly distributed with a

737 mean of 0.291 and 0.266 , respectively. $\mathrm{NIR}_{\mathrm{V}}$ was comparatively leptokurtic, with a lower

738 mean of 0.161.

$740 \quad$ 3.3. Distribution attribution: Random Forest classification

741 At this stage, the second accuracy assessment was conducted to determine whether

742 the RF model yielded any gain or loss of skill over temporal segmentation. Accuracy was

743 assessed in the same manner as in the first stage, except that reference points were now

744 compared to RF-modeled images rather than the original temporal-segmentation outputs.

745 Overall accuracy was $80.0 \%$ for Model $1(\kappa=0.700)$ and $79.8 \%$ for Model $2(\kappa=0.697)$, with

746 no significant difference between the two $(p>0.01)$. However, $\mathrm{RF}$ was more adept at

747 differentiating disturbance, stable forest, and stable non-forest than the temporal

748 segmentation procedure alone. Overall accuracy increased with RF modeling by between

$749 \quad 5.6 \%$ and $10.7 \%(\mathrm{p}<0.01)$.

750 Agent attribution accuracy was then assessed using the RF models' OOB diagnostics

751 (Table 7). The first model, which excluded textural variables, showed an overall agreement

752 of $72.0 \%$ and $\kappa=0.650$. The second model, which included the texture metrics, had an

753 overall agreement of $72.2 \%$ and $\kappa=0.652$. The difference in accuracy between the models

754 was insignificant $(\mathrm{p}>0.01)$. 
756 non-forest had the highest model agreement with reference data (refer to the "CE" column

757 and "OE" row in Table 7). Model errors for these classes were relatively well balanced—OE

758 and CE scores fell within $\pm 10 \%$ of each other-which suggests that the model was

759 appropriately tuned to the data. Stable forest and harvest were also well balanced, but

760 their errors were higher (> 35.0\%), and they were systematically confused with one another

761 (60 instances in Table 7a and 47 instances in Table 7b). Fire's accuracy was moderate

762 (balanced accuracy $=79.8 \%$ in Model 1 and $76.0 \%$ in Model 2), but it was frequently

763 confused with all other classes except non-forest, as the false-positive and false-negative

764 entries along the "Fire" row and column indicate.

765

766 3.4. Predictor variable importance

767 Table 8 reports predictor variable importance in terms of the decrease in overall

768 model accuracy (mean decrease in accuracy, MDA) that would result if a given variable

769 were excluded from the model. The three most powerful predictors in both models were the

770 land-cover ternary generated from NDVI segmentation, elevation, and fractal dimension

771 computed on NDVI. Fractal dimension from all three vegetation indices emerged in the top

77215 explainers in both models. In the second model, the texture metrics appeared to promote

773 the relative importance of slope. While texture metrics added comparatively little

774 explanatory power, entropy was the highest-ranked contributor of the texture metrics.

775 Notably, in Model 2, the absolute values of predictor MDA decrease for all variables,

776 despite similar rankings. This suggests that textures are not simply "noisy" predictors but

777 contribute information to the classification decision; they also appear to balance the overall

778 distribution of importance across predictors. 
The predicted forest disturbance agents were mapped alongside stable forest and

782 non-forest predictions (Fig. 9). The maps confirm that the models were able to distinguish

783 effectively among disturbance agent classes.

784 The models were particularly sensitive to differences between fire and stress, which

785 tended to co-occur at lower elevations. However, the error matrices revealed high rates of

786 false-positive stress identification; this occurred mostly around the margins of fire

787 perimeters, suggesting that the models may confuse stress with low-intensity fire. In

788 general, mapped predictions of fire were well resolved and agreed closely with CalFire

789 FRAP perimeters.

790 The overprediction of harvest identified in the error matrices bears out in the maps.

791 In reality, harvest is generally constrained between $1000-1500 \mathrm{~m}$. Harvest does appear less

792 frequently in the northern and eastern sections of the maps; these unharvested areas

793 closely match the Mokelumne, Carson-Iceberg, and Emigrant Wilderness boundaries,

794 where harvest is proscribed. These areas also occur at higher elevations, which points to

795 the strong effect of elevation in the models. Notable exceptions are the distinctive narrow

796 stretches identified as harvest in the easternmost portions of the maps. These follow the

797 Clark and Middle Forks of the Stanislaus River and are contained within Carson-Iceberg

798 Wilderness. There is no record of harvest in these areas in the LANDFIRE reference data.

799 Among the predicted disturbance agent classes, harvest was the most prevalent,

800 followed by fire and stress (Fig. 10). Forest persisted in more than $40 \%$ of the area over the

801 study period. Because the analysis is temporally indifferent and does not account for

802 regeneration, any pixel identified as disturbed retains this status, regardless of when the

803 disturbance was detected. 
804 Because elevation proved to be a strong predictor, I further analyzed the

805 relationship between elevation and disturbance agent prevalence (Fig. 11). Stable forest

806 was widely distributed across elevations up to $\sim 2800 \mathrm{~m}$, and non-forest was self-evidently

807 concentrated at altitudes above $2000 \mathrm{~m}$ (i.e., exposed granite batholith and alpine vegetation

808 communities). Harvest appeared to be more constrained to mid-elevations, while fire and

809 stress tended to co-occur at lower elevations, as is evident in the varying means, $x$-widths

810 and $y$-densities of the violin plots.

811

812 4. Discussion

813

814 4.1. Conceptual challenges

815 As patterns of forest disturbance continue to shift in the Sierra Nevada of California,

816 it is imperative that forest monitoring programs efficiently and accurately resolve not only

817 the spatial and temporal qualities of disturbance events, but also their causes. Disturbance

818 agents have variable impacts on forest composition, structure, and function, and effective

819 forest management will increasingly depend on robust estimates of prior disturbance-agent

820 prevalence as well as skillful predictions of future trends. An ideal product to satisfy this

821 need would be an accurate, full-coverage map of historical disturbance that (a) renders the

822 events explicitly in space and time, (b) accounts for their drivers, and (c) can be readily

823 produced and updated with minimal analyst oversight. Achieving such an ideal through a

824 modeling approach requires overcoming at least three major challenges. First is the basic

825 difficulty of differentiating change agents (Kennedy et al. 2015). Disturbance is not

826 inherently related to the spectral signals captured by most remote sensors, and different

827 agents of disturbance can leave identical spectral signatures. While spectral information

828 contributes substantially to disturbance detection (Cohen et al. 2018) and goes part of the 
829 way toward agent attribution (Schroeder et al. 2017, Shimizu et al. 2019b), additional

830 information about the landscape and the processes manifest on it is necessary for a reliable

831 and generalizable approach. A second challenge is spatial scale. Remote sensing operates at

832 the scale of the pixel and is for the most part limited by the native resolution of satellite

833 and aerial sensors (although the increasing availability of very high-resolution images and

834 the promising development of new data fusion methods are rapidly diminishing the size of

835 this challenge) (Cakir et al. 2006, Khorram et al. 2016). Ecological processes occur at scales

836 much smaller and much larger than the 30-m pixel used in this study. Disturbances affect

837 individual trees, and they affect entire landscapes. Reliance on pixel scale means accepting

838 error at both ends: in generalization of sub-pixel information and in over-specification of

839 behavior that is in fact occurring across aggregations of pixels. The third challenge has to

840 do with heterogeneity in the spatial extent, temporal duration, and intensity of

841 disturbances' impacts on vegetation. Variability in harvest densities, for instance, yields

842 considerable heterogeneity within what would ideally be considered a uniform category of

843 change agent. The same can be said for variable-density thinning treatments, species-

844 selective beetle kill, and fire. Here, I have described an approach that incrementally

845 advances the field toward addressing these challenges.

846

847 4.2. Disturbance detection

848 In simply detecting disturbances, the RF model performed better than the temporal

849 segmentation procedures run on NDVI, NBR, and NIRV time-series stacks. This additional

850 improvement from RF was likely the result of combining information from multiple spectral

851 indices. Indeed, this was consistent with recent findings in the literature that combining

852 multiple indices can yield higher detection accuracy (Kennedy et al. 2015, Schroeder et al.

853 2017). The hypothesized reason for this effect is that no single index accounts for the full 
854 range of spectral behavior in a disturbed forested landscape. The fact that detection

855 accuracy was not significantly different when any single index was used further confirms

856 this inference.

857 Given these results, NIRv did not appear to aid disturbance detection on its own. It

858 did not appear to detract either, although the indices were not tested systematically against

859 one another. NIR $\mathrm{V}$ captured a broader range of vegetation changes than NDVI and NBR,

860 based on its greater total identification of disturbed pixels. Higher peaks and positive skew

861 in the distributions of raw $\mathrm{NIR}_{V}$ values and $\Delta \mathrm{NIR}_{\mathrm{V}}$ values suggested that $\mathrm{NIR}_{\mathrm{V}}$ was more

862 sensitive to subtler negative changes in vegetation than the other two indices were.

863 However, this behavior may have also been driven by the NIR multiplier in the NIRV

864 calculation or by noisy false-positive detection.

865 In any case, the total number of disturbed pixels identified across the three indices

866 (Fig. 7) appeared to vary more consistently with year of detection than with index. While

867 NBR's disturbed total consistently exceeded that of the other two indices in low-disturbance

868 years, NDVI was anomalously high in 2014 and anomalously low in 2013. NIRv total

869 disturbed was anomalously high in 2013. No ready pattern emerges from this behavior.

870 However, 2013 and 2014 witnessed the Rim Fire, represented in Fig. 9 by the large swath

871 of fire-attributed pixels in the southern third of the maps. This was immediately predated

872 by intense drought-related desiccation stress in 2012-2013. It may be the case that NIRV is

873 more sensitive to stress responses, while NDVI is more sensitive to fire responses. On this

874 interpretation, NBR's moderate detection of fire may be more accurate. The Rim Fire years

875 notwithstanding, there was no obvious increasing or decreasing trend in total disturbance

876 evident over time, though a discernible trend would not necessarily be expected on a 16-

877 year timescale. 


\subsection{Agent attribution}

880 The procedure appeared to capture the broad categories of disturbance operating in

881 Stanislaus National Forest between 1999 and 2015. The results underscore the need to

882 incorporate data beyond first-order spectral-reflectance metrics. Two measures of landscape

883 position, elevation and slope, ranked among the top five predictors in both models. Their

884 relative importance is most likely a consequence of how these topographical characteristics

885 regulate the presence and structure of vegetation. Topography also influences disturbance

886 processes: harvest tends to occur at lower elevations and on shallower slopes; fire has been

887 found to spread more rapidly on steeply inclining slopes and to burn more intensely on

888 steeply declining slopes. Some of the beetle infestations of the early 2010s also occurred

889 within distinct elevation bands, partially a result of elevational controls on tree species

890 distributions. Fractal dimension is a landscape shape metric several processing steps

891 removed from raw spectral returns, yet it was the third strongest explainer in both models.

892 This hints at the importance of scale in this modeling approach; fractal dimension exploits

893 the sizes and shapes of disturbed patches, while other predictors in the set primarily act at

894 the pixel scale. Spatial extent is a key characteristic of disturbance legacies and is

895 frequently differentiable by agent on the ground. Its appearance as one of the more

896 important predictors squares with this observation.

897 The overall skill of the model, evaluated in terms of model accuracy ( 72\%) was

898 reasonable, but not exceptional. Per-class accuracy ranges between 71\% and 100\% were on

899 par with the those in the most successful agent-attribution models in the literature

900 (Kennedy et al. 2015, Schroeder et al. 2017, Shimizu et al. 2019a). Those studies yielded

901 higher overall accuracy values than the method in this paper (78-95\%). Their $\kappa$ statistics

902 ranged between 0.40 and 0.85. In the Schroeder et al. (2017) study, the scene that

903 overlapped Stanislaus National Forest actually returned the highest accuracy rate (95\%) of 
904 all of the scenes in their investigation. My results were significantly less robust, despite

905 similar agent-class groupings, reference data, and input variables in the texture-free model.

906 One reason for the discrepancy could be that Schroeder et al.'s time series ended in 2010,

907 before the major drought and Rim Fire; their observations may have included less stress-

908 related spectral change overall, which may have dampened confusion of stable forest,

909 harvest, and stress. Another major divergence was that they used VCT for temporal

910 segmentation; it would be worthwhile to test the impacts of assimilating VCT-derived vs

911 Landtrendr-derived disturbance metrics for agent attribution in the future.

912 At the class level, considerable confusion arose between stable forest and harvest,

913 resulting in systematic overprediction of harvest. Commission error for harvest exceeded

9140.45 in both models. The confusion here likely results from different mechanical harvest

915 treatments being compressed into one category. Selective removal and thinning were

916 grouped together with clear-cuts, a decision that likely expanded the dimensional space for

917 harvest enough that it caused model votes for harvest to also capture stable forest. The

918 balanced omission and commission errors for these two classes is a good indicator that this

919 was the case. A second source of error may have been the masking of stable forest pixels in

920 several of the predictors (i.e., magnitude, year of detection, rate, fractal dimension, and the

921 three texture metrics). Masking was the best solution to an intractable dilemma: using full

922 coverage data for those metrics would have entailed assimilating a separate image for each

923 year. For the texture metrics alone, this would have yielded 153 distinct images (3 variables

924 x 3 indices x 17 years), a rate of expansion that would have quickly exhausted available

925 computing capacity and likely would have biased the model toward the orders-of-magnitude

926 more prevalent variable types. In fact, in early iterations of the model, I tested this

927 possibility using full-coverage annual textures for NIRv alone. The model skill was

928 insignificantly different from the model described in this paper. And although textures did 
929 contribute a greater share of predictive power, this likely had more to do with their

930 dominance of the share of predictors.

931

932 4.4. Spatial patterns and prospects for application

933 With the exception of overpredicted harvest, the location and distribution of

934 attributed change agents cohered with expectations for the study site, from the minimum-

935 mapping unit scale of one hectare up to the full National Forest scale. The fact that

936 reasonably accurate disturbance-agent predictions can be made with a very small

937 proportion of pixels used as training points ( $0.07 \%$ of total) underscores the promiseof thise

938 approach for reducing the time and resource requirements of agent-explicit disturbance

939 detection at the landscape scale.

940

941 4.5. Contribution of texture metrics

942 Textures contributed not at all to the absolute accuracy of the models and only

943 negligibly in terms of the relative importance of predictors. The insignificant results mean

944 that the null hypothesis cannot be rejected, and that textures have little effect on the

945 modeling method's predictive skill. Several inferences seem plausible. The first is that

946 textural information may straightforwardly fail to add power to differentiate among

947 disturbance legacies. This would seem to be confirmed by the null difference in overall

948 model accuracy. A second interpretation is that textural information contributes to skill,

949 but it is a much weaker explainer than the topographic and shape variables that drive most

950 of the prediction. This would seem to be confirmed by the appearance of the NDVI entropy

951 metric among the top ten predictors in the second model.

952 One important limitation confronts interpretation of individual predictor

953 importance. Because of RF's tendency to distribute importance across correlated variables, 
954 retaining correlates in the set will also influence the relative importance of independent

955 metrics. Several of the variables were correlated; most of those derived directly from

956 temporal segmentation (i.e., the "Disturbance" category in Appendix B) had paired

957 Pearson's $r$ coefficients $>0.50(p<0.01)$. On the whole, the texture metrics were not well

958 correlated with any other variables $(r<0.30, \mathrm{p}<0.01)$. One exception was entropy, which

959 varied with all of the "Disturbance" variables $(r>0.50, \mathrm{p}<0.01)$.

960 In the course of this study, I was unable to adjust satisfactorily for this distortion. In

961 prior disturbance agent attribution studies, authors have either ignored the variable

962 interdependence problem or computed a rank sum of importance for groupings of correlated

963 variables (Schroeder et al. 2014); this requires observations from multiple independent

964 model replicates and so was infeasible for this single-domain study. Another solution might

965 be to systematically remove variables from correlated pairs. However, exploratory tests of

966 this approach significantly reduced model skill and so were rejected for this project. A third

967 option could be to use factor analysis to compress the variable set into a smaller collection

968 of uncorrelated factors and to rank this smaller collection according to a sum or mean rule.

969 This seems like a promising direction, but acquiring an honest operational understanding

970 of factor analysis exceeded the scope of an already capacious project.

971 In sum, while care was taken to identify independent measures of texture in order to

972 evaluate their importance in comparison with one another, inferences about any variable's

973 overall rank in the predictor set may be distorted by interdependences among other

974 variables. Accordingly, there are limits to the inferences that can be drawn from variable

975 importance.

976 It may be the case that landscape textures are important for discriminating

977 disturbance legacies, but that texture was insufficiently operationalized in this study. One

978 potential weakness was the aforementioned masking of stable forest and stable non-forest 
979 in several of the predictors. In future work, it would be advisable to study a smaller area

980 over a shorter timescale, focusing on pixels where only stable forest and harvest co-occur.

981 Including full-coverage spectral and textural metrics in this case could improve model skill

982 markedly.

983 Another underexplored area is the spatial scale of texture computation. The ability

984 of edge and interior texture metrics to differentiate disturbance agents is necessarily a

985 function of the scale at which disturbance occurs. Calculated in a 3x3 pixel neighborhood,

986 contrast was robust to edges of harvested and stressed patches (Fig. 6). Correlation and

987 entropy were less adept at discriminating among interior behaviors in disturbed and stable

988 patches. A promising direction for further study would be to evaluate a wider range of

989 neighborhood sizes. Including 24-neighbor and 224-neighbor iterations, for example, might

990 help to identify interior patch structures that aren't detectable in an eight-neighbor

991 window. This information could enhance the contribution of textural metrics.

992 Finally, a major unresolved issue for this study and other agent-attribution

993 approaches is the lack of an external reference dataset with sufficient temporal and spatial

994 resolution across the length of the Landsat record to use for independent model training

995 and validation. This is something of a chicken-and-egg problem. Using incomplete ancillary

996 datasets and records to manually verify disturbance occurrence and agent class for 1000

997 training points is a tedious and error-prone exercise that further underscores the need for a

998 more reliable modeling approach. But in the absence of a valid independent reference, a

999 generalizable modeling approach remains difficult to achieve. A randomly sampled and

1000 verified set of retrospective disturbance points with error terms would help to an extent.

1001 However, because of the conceptual fuzziness of ecological disturbance noted in the

1002 introduction to this paper, an absolute reference may be inherently elusive, especially for

1003 agent classes that are difficult to differentiate even through on-the-ground study, such as 
1004 drought stress and beetle kill. In light of this constraint, most agent-attribution approaches

1005 have aimed not for perfect classification agreement, but for improvement over the

1006 inconsistent and discontinuous data products currently in widespread application in forest

1007 management. Acknowledging that the approach described here inherits some uncertainty

1008 from reference data, remotely sensed data, and model decisions alike, it still succeeds on

1009 this more modest criterion of incremental improvement.

1010

1011 5. Conclusions

1012

1013 The objective of this project was to develop and test an integrated empirical

1014 modeling method for attributing forest disturbances to particular agents. The motivation

1015 was twofold: to advance a burgeoning field of methodological inquiry in the remote sensing

1016 of forest resources and to enhance the information streams available to resource and

1017 conservation managers for decision-making regarding disturbance adaptation and

1018 mitigation. The approach presented here satisfies both. The method yields adequate

1019 identification of disturbance location and moderate attribution accuracy for multiple

1020 disturbance agents. While texture as it was operationalized here did not meaningfully

1021 contribute to model skill, the results further confirm that information beyond spectral

1022 reflectance records is required for accurate agent attribution. As a proof-of-concept, this

1023 study offers a strong foundation for future work, which should focus on improving the

1024 overall efficacy of the models and generalizing them for systems beyond the Central Sierra

1025 Nevada.

1026 


\section{Literature Cited}

1028

Adams, H. D., M. Guardiola-Claramonte, G. A. Barron-Gafford, J. Camilo Villegas, D. D. N. Cobb. 2010. A global overview of drought and heat-induced tree mortality reveals emerging climate change risks for forests. Forest Ecology and Management 259:660684.

Anderegg, W. R. L., J. A. Hicke, R. A. Fisher, C. D. Allen, J. Aukema, B. Bentz, S. Hood, J. W. Lichstein, A. K. Macalady, N. McDowell, Y. Pan, K. Raffa, A. Sala, J. D. Shaw, N. L. Stephenson, C. Tague, and M. Zeppel. 2015. Tree mortality from drought, insects, and their interactions in a changing climate. New Phytologist 208:674-683.

Badgley, G., L. D. L. Anderegg, J. A. Berry, and C. B. Field. 2019. Terrestrial gross primary production: Using NIRV to scale from site to globe. Global Change Biology 25:37313740.

Badgley, G., C. B. Field, and J. A. Berry. 2017. Canopy near-infrared reflectance and terrestrial photosynthesis. Science Advances 3:1-6.

Beisner, B. E., D. T. Haydon, and K. Cuddington. 2003. Alternative stable states in ecology. Frontiers in Ecology and the Environment 1:376-382.

Birdsey, R., A. Dugan, S. Healey, K. Dante-Wood, F. Zhang, J. Chen, A. Hernandez, C. 
Raymond, and J. McCarter. 2019. Assessment of the influence of disturbance, management activities, and environmental factors on carbon stocks of United States National Forests. General Technical Report RMRS-GTR-402, U.S. Department of Agriculture, Forest Service, Rocky Mountain Research Station. Fort Collins, Colorado, USA.

Braziunas, K. H., W. D. Hansen, R. Seidl, W. Rammer, and M. G. Turner. 2018. Looking beyond the mean: drivers of variability in postfire stand development of conifers in

Breiman, L. 2001. Random forests. Machine Learning 45:5-32.

1061 Breshears, D. D., N. S. Cobb, P. M. Rich, K. P. Price, C. D. Allen, R. G. Balice, W. H. Romme, J. H. Kastens, M. L. Floyd, J. Belnap, J. J. Anderson, O. B. Myers, and C. W. Meyer. 2005. Regional vegetation die-off in response to global-change-type drought.

Cakir, H. I., S. Khorram, and S. A. C. Nelson. 2006. Correspondence analysis for detecting land cover change. Remote Sensing of Environment 102:306-317.

1068 Christensen, G. A., K. L. Waddell, S. M. Stanton, and O. Kuegler. 2016. California's forest resources: Forest Inventory and Analysis, 2001-2010. General technical report PNW-

1072 Ciesla, W. M. 2000. Remote sensing in forest health protection. FHTET Report 00-03.

1073 Remote U.S. Department of Agriculture, Forest Service, Remote Sensing Applications 1074 Center. Salt Lake City, Utah, USA.

1075 Clark, J. S., L. Iverson, C. W. Woodall, C. D. Allen, D. M. Bell, D. C. Bragg, A. W. D. Amato, 1076 F. W. Davis, M. H. Hersh, I. Ibanez, S. T. Jackson, S. Matthews, N. Pederson, M. 
Peters, M. W. Schwartz, K. M. Waring, and N. E. Zimmerman. 2016. The impacts of increasing drought on forest dynamics, structure, and biodiversity in the United

Coburn, C. A., and A. C. B. Roberts. 2004. A multiscale texture analysis procedure for improved forest stand classification. International Journal of Remote Sensing 25:4287-

Cochrane, M. A., and K. C. Ryan. 2009. Fire and fire ecology: concepts and principles. Pages 25-62 in M. A. Cochrane, editor. Tropical fire ecology: climate change, land use, and ecosystem dynamics. Praxis Publishing, Chichester, UK.

1086 Cohen, W. B., Z. Yang, S. P. Healey, R. E. Kennedy, and N. Gorelick. 2018. A LandTrendr multispectral ensemble for forest disturbance detection. Remote Sensing of and G. W. Meigs. 2016. Forest disturbance across the conterminous United States from 1985-2012: the emerging dominance of forest decline. Forest Ecology and Management in the northern Sierra Nevada, California, USA. Landscape Ecology 28:1801-1813. Reconstructing past fire regimes: methods, applications, and relevance to fire management and conservation. Quaternary Science Reviews 28:555-576.

Connell, J. H., and W. P. Sousa. 1983. On the evidence needed to judge ecological stability or persistence. American Naturalist 121:789-824.

Coop, J. D., S. A. Parks, S. R. McClernan, and L. M. Holsinger. 2016. Influences of prior wildfires on vegetation response to subsequent fire in a reburned southwestern 
landscape. Ecological Applications 26:346-354.

1103 Crockett, J. L., and A. L. Westerling. 2018. Greater temperature and precipitation extremes

1104 intensify Western U.S. droughts, wildfire severity, and Sierra Nevada tree mortality.

1105 Journal of Climate 31:341-354.

1106 Dale, V. H., L. A. Joyce, S. McNulty, R. P. Neilson, M. P. Ayres, M. D. Flannigan, P. J.

1107 Hanson, L. C. Irland, A. E. Lugo, C. J. Peterson, D. Simberloff, F. J. Swanson, B. J.

1108 Stocks, and B. Michael Wotton. 2001. Climate change and forest disturbances.

1109 BioScience 51:723-734.

1110 Dolanc, C. R., H. D. Safford, S. Z. Dobrowski, and J. H. Thorne. 2014. Twentieth century

1111 shifts in abundance and composition of vegetation types of the Sierra Nevada, CA, US.

1112 Applied Vegetation Science 17:442-455.

1113 Dolanc, C. R., J. H. Thorne, and H. D. Safford. 2013. Widespread shifts in the demographic

1114 structure of subalpine forests in the Sierra Nevada, California, 1934 to 2007. Global

1115 Ecology and Biogeography 22:264-276.

1116 Eidenshink, J., B. Schwind, K. Brewer, Z. Zhu, B. Quayle, and S. Howard. 2007. A project

1117 for monitoring trends in burn severity. Fire Ecology 3:3-21.

1118 Fettig, C. J., L. A. Mortenson, B. M. Bulaon, and P. B. Foulk. 2019. Tree mortality following

1119 drought in the central and southern Sierra Nevada, California, U.S. Forest Ecology

$1120 \quad$ and Management 432:164-178.

1121 Foody, G. M. 2002. Status of land cover classification accuracy assessment. Remote Sensing

1122 of Environment 80:185-201.

1123 Franklin, J. F., T. A. Spies, R. Van Pelt, A. B. Carey, D. A. Thornburgh, D. R. Berg, D. B.

1124 Lindenmayer, M. E. Harmon, W. S. Keeton, D. C. Shaw, K. Bible, and J. Chen. 2002.

1125 Disturbances and structural development of natural forest ecosystems with

1126 silvicultural implications, using Douglas-fir forests as an example. Forest Ecology and 
1128 Freeman, E. A., T. S. Frescino, and G. G. Moisen. 2016. ModelMap: an R package for model creation and map production. https://cran.r-project.org/web/packages/ModelMap/

1131 Freeman, E. A., G. G. Moisen, J. W. Coulston, and B. T. Wilson. 2015. Random forests and stochastic gradient boosting for predicting tree canopy cover: Comparing tuning processes and model performance. Canadian Journal of Forest Research 46:323-339.

Fukami, T., and M. Nakajima. 2011. Community assembly: alternative stable states or

1136 Fung, T., and E. Ledrew. 1987. Application of principal components analysis to change detection. Photogrammetric Engineering \& Remote Sensing 53:1649-1658. Thematic Mapper data. International Journal of Remote Sensing 22:533-549.

1140 Goodwin, N. R., N. C. Coops, M. A. Wulder, S. Gillanders, T. A. Schroeder, and T. Nelson. 2008. Estimation of insect infestation dynamics using a temporal sequence of Landsat

1143 Gorelick, N., M. Hancher, M. Dixon, S. Ilyushchenko, D. Thau, and R. Moore. 2017. Google 1144 Earth Engine: planetary-scale geospatial analysis for everyone. Remote Sensing of $1145 \quad$ Environment 202:18-27.

1146 Goward, S. N., C. Huang, F. Zhao, K. Schleeweis, K. Rishmawi, M. Lindsey, J. L. Dungan, 1147 and A. Michaelis. 2016. NACP North American Forest Dynamics Project: forest 1148 disturbance history from Landsat, 1986-2010. ORNL Distributed Active Archive 1149 Center, Oak Ridge, Tennessee, USA.

1150 Hadfield, J. S. 1968. Color infrared photography effectively detects pines killed by Fomes 1151 annosus. Pages 37-42 in C. W. . Hodges, J. Risbeth, and A. Yde-Anderson, editors. 
Proceedings of the Third International Conference on Fomes annosus. U.S.

1153 Department of Agriculture, Forest Service, Washington, D.C., USA.

1154 Hall-Beyer, M. 2017. Practical guidelines for choosing GLCM textures to use in landscape

1155 classification tasks over a range of moderate spatial scales. International Journal of

$1156 \quad$ Remote Sensing 38:1312-1338.

1157 Hansen, W. D., and M. G. Turner. 2019. Origins of abrupt change? Postfire subalpine

1158 conifer regeneration declines nonlinearly with warming and drying. Ecological

$1159 \quad$ Monographs 89:e01340.

1160 Hanson, J. B., and W. Lautz. 1971. Photography as an aid in estimating Annosus root rot$1161 \quad$ caused tree mortality. Plant Disease Reporter 55:761-763.

1162 Haralick, R. M., K. Shanmugam, and I. Dinstein. 1973. Textural features for image

1163 classification. IEEE Transactions on Systems, Man and Cybernetics SMC-3:610-621.

1164 Hargrove, W., J. P. Spruce, G. E. Gasser, and F. M. Hoffman. 2009. Toward a national early

1165 warning system for forest disturbances using remotely sensed canopy phenology.

1166 Photogrammetric Engineering \& Remote Sensing 75:1150-1156.

1167 Heller, R. C., R. C. Aldrich, and W. F. Bailey. 1959. An evaluation of aerial photography for

1168 detecting southern pine beetle damage. Photogrammetric Engineering 25:595-606.

1169 Huang, C., S. N. Goward, J. G. Masek, N. Thomas, Z. Zhu, and J. E. Vogelmann. 2010. An

1170 automated approach for reconstructing recent forest disturbance history using dense

1171 Landsat time series stacks. Remote Sensing of Environment 114:183-198.

1172 Iverson, L. R., R. L. Graham, and E. A. Cook. 1989. Applications of satellite remote sensing

1173 to forested ecosystems. Landscape Ecology 3:131-143.

1174 Johnstone, J. F., C. D. Allen, J. F. Franklin, L. E. Frelich, B. J. Harvey, P. E. Higuera, M.

1175 C. Mack, R. K. Meentemeyer, M. R. Metz, G. L. W. Perry, T. Schoennagel, and M. G.

1176 Turner. 2016. Changing disturbance regimes, ecological memory, and forest resilience. 
Frontiers in Ecology and the Environment 14:369-378.

1178 Keeley, J. E. 2009. Fire intensity, fire severity and burn severity: a brief review and suggested usage. International Journal of Wildland Fire 18:116-126.

1180 Kennedy, R. E., Z. Yang, J. Braaten, C. Copass, N. Antonova, C. Jordan, and P. Nelson. 2015. Attribution of disturbance change agent from Landsat time-series in support of

Kennedy, R. E., Z. Yang, and W. B. Cohen. 2010. Detecting trends in forest disturbance and

1187 Kennedy, R. E., Z. Yang, N. Gorelick, J. Braaten, L. Cavalcante, W. B. Cohen, and S. recovery using yearly Landsat time series: 1. LandTrendr — Temporal segmentation Healey. 2018. Implementation of the LandTrendr algorithm on Google Earth Engine.

Kim, M., M. Madden, and T. A. Warner. 2009. Forest type mapping using object-specific Remote Sensing 10:1-10.

Khorram, S., C. F. van der Wiele, F. H. Koch, S. A. C. Nelson, and M. D. Potts. 2016. texture measures from multispectral Ikonos imagery: segmentation quality and image

1198 Larvie, K., T. Moody, J. Axelson, C. Fettig, and P. Cafferata. 2018. Synthesis of research 1199 into the long-term outlook for Sierra Nevada forests following the current bark beetle $1200 \quad$ epidemic. California forestry note 122. California Natural Resources Agency, 1201 Department of Forestry and Fire Protection. Sacramento, CA, USA. 
1202 Lu, D., P. Mausel, E. Brondízio, and E. Moran. 2004. Change detection techniques.

1203 International Journal of Remote Sensing 25:2365-2401.

1204 Lund, H. G. 1997. Forestry. Pages 399-440 in W. Philipson, editor. Manual of Photographic

1205 Interpretation. 2nd edition. American Society for Photogrammetry \& Remote Sensing,

$1206 \quad$ Bethesda, Maryland, USA.

1207 Marceau, D. J., P. J. Howarth, J. M. M. Dubois, and D. J. Gratton. 1990. Evaluation of the

1208 grey-level co-occurrence matrix method for land-cover classification using SPOT

1209 imagery. IEEE Transactions on Geoscience and Remote Sensing 28:513-519.

1210 McDowell, N. G., N. C. Coops, P. S. A. Beck, J. Q. Chambers, C. Gangodagamage, J. A.

1211 Hicke, C.-Y. Huang, R. Kennedy, D. J. Krofcheck, M. Litvak, A. J. H. Meddens, J.

1212 Muss, R. Negrón-Juarez, C. Peng, A. M. Schwantes, J. J. Swenson, L. J. Vernon, A. P.

1213 Williams, C. Xu, M. Zhao, S. W. Running, and C. D. Allen. 2015. Global satellite

1214 monitoring of climate-induced vegetation disturbances. Trends in Plant Science

$1215 \quad 20: 114-123$.

1216 Millar, C. I., R. D. Westfall, D. L. Delany, M. J. Bokach, A. L. Flint, and L. E. Flint. 2012.

1217 Forest mortality in high-elevation whitebark pine (Pinus albicaulis) forests of eastern

1218 California, USA; influence of environmental context, bark beetles, climatic water

1219 deficit, and warming. Canadian Journal of Forest Research 42:749-765.

1220 Millar, C., N. L. Stephenson, and S. L. Stephens. 2007. Climate change and forests of the

1221 future: managing in the face of uncertainty. Ecological Applications 17:2145-2151.

1222 Miller, J. D., H. D. Safford, M. Crimmins, and A. E. Thode. 2009. Quantitative evidence for

1223 increasing forest fire severity in the Sierra Nevada and southern Cascade Mountains,

1224 California and Nevada, USA. Ecosystems 12:16-32.

1225 Neigh, C. S. R., D. K. Bolton, M. Diabate, J. J. Williams, and N. Carvalhais. 2014a. An

1226 automated approach to map the history of forest disturbance from insect mortality and 
harvest with landsat time-series data. Remote Sensing 6:2782-2808.

1228 Neigh, C. S. R., D. K. Bolton, J. J. Williams, and M. Diabate. 2014b. Evaluating an

automated approach for monitoring forest disturbances in the Pacific Northwest from logging, fire and insect outbreaks with landsat time series data. Forests 5:3169-3198.

1231 Oeser, J., D. Pflugmacher, C. Senf, M. Heurich, and P. Hostert. 2017. Using intra-annual 1232 Landsat time series for attributing forest disturbance agents in Central Europe.

$1233 \quad$ Forests 8:doi:10.3390/f8070251.

1234 Oswalt, S. N., W. B. Smith, P. D. Miles, and S. A. Pugh. 2019. Forest resources of the 1235 United States, 2017: a technical document supporting the Forest Service 2020 RPA 1236 Assessment. General Technical Report WO-97. U.S. Department of Agriculture, Forest 1237 Service. Washington, D.C., USA.

1238 Ozdemir, I., A. Mert, and O. Senturk. 2012. Predicting landscape structural metrics using 1239 ASTER satellite data. Journal of Environmental Engineering and Landscape $1240 \quad$ Management 20:168-176.

1241 Paz-Kagan, T., P. G. Brodrick, N. R. Vaughn, A. J. Das, N. L. Stephenson, K. R. Nydick, 1242 and G. P. Asner. 2017. What mediates tree mortality during drought in the southern $1243 \quad$ Sierra Nevada? Ecological Applications 27:2443-2457.

1244 Perry, D. A., P. F. Hessburg, C. N. Skinner, T. A. Spies, S. L. Stephens, A. H. Taylor, J. F. 1245 Franklin, B. McComb, and G. Riegel. 2011. The ecology of mixed severity fire regimes 1246 in Washington, Oregon, and Northern California. Forest Ecology and Management $1247 \quad 262: 703-717$.

1248 Peters, D. P. C., A. E. Lugo, F. S. Chapin, S. T. A. Pickett, M. Duniway, A. V. Rocha, F. J. 1249 Swanson, C. Laney, and J. Jones. 2011. Cross-system comparisons elucidate 1250 disturbance complexities and generalities. Ecosphere 2:1-26.

1251 Potter, C. 2014. Ten years of forest cover change in the Sierra Nevada detected using 

7153.

1254 Potter, C., V. Genovese, P. Gross, S. Boriah, M. Steinbach, and V. Kumar. 2007. Revealing

1255 land cover change in California with satellite data. Eos 88:269-276.

1256 Potter, C. S. 2017. Satellite image mapping of tree mortality in the Sierra Nevada region of 1257 California from 2013 to 2016. Journal of Biodiversity Management \& Forestry 6:10.4172/2327-4417.1000176.

R Core Team. 2014. R: a language and environment for statistical computing. R Foundation

Rollins, M. G. 2009. LANDFIRE: A nationally consistent vegetation, wildland fire, and fuel for Statistical Computing, Vienna, Austria. http://www.r-project.org/.

1263 Rouse, J. W., R. H. Hass, J. A. Schell, and D. W. Deering. 1974. Monitoring vegetation 1264 systems in the great plains with ERTS. Pages 309-317 in S. C. Freden, E. P. Mercanti, 1265 and M. A. Becker, editors. Third Earth Resources Technology Satellite-1 (ERTS) Symposium Vol. 1: Technical Presentations. NASA Goddard Space Flight Center,

1268 Roy, D. P., V. Kovalskyy, H. K. Zhang, E. F. Vermote, L. Yan, S. S. Kumar, and A. Egorov. 2016. Characterization of Landsat- 7 to Landsat- 8 reflective wavelength and

1272 Schmidt, C. 2014. Challenges to Sierra Nevada forests and their local communities: an normalized difference vegetation index continuity. Remote Sensing of Environment

1275 Schroeder, T. A., S. P. Healey, G. G. Moisen, T. S. Frescino, W. B. Cohen, C. Huang, R. E. 1276 Kennedy, and Z. Yang. 2014. Improving estimates of forest disturbance by combining 
observations from Landsat time series with U.S. Forest Service Forest Inventory and Analysis data. Remote Sensing of Environment 154:61-73.

Schroeder, T. A., K. G. Schleeweis, G. G. Moisen, C. Toney, W. B. Cohen, E. A. Freeman, Z.

Seidl, R., and W. Rammer. 2017. Climate change amplifies the interactions between wind Yang, and C. Huang. 2017. Testing a Landsat-based approach for mapping disturbance and bark beetle disturbances in forest landscapes. Landscape Ecology 32:1485-1498. series. Remote Sensing of Environment 170:166-177.

Shimizu, K., O. S. Ahmed, R. Ponce-Hernandez, T. Ota, Z. C. Win, N. Mizoue, and S.

Shimizu, K., T. Ota, and N. Mizoue. 2019a. Detecting forest changes using dense Landsat 8 Yoshida. 2017. Attribution of disturbance agents to forest change using a Landsat time Stephens. 2018. From the stand scale to the landscape scale: predicting the spatial disturbance agent classification approaches: strengths of ensemble classification, multiple indices, spatio-temporal variables, and direct prediction. Journal of Photogrammetry and Remote Sensing 158:99-112. patterns of forest regeneration after disturbance. Ecological Applications 28:16261639.

Simler, A. B., M. R. Metz, K. M. Frangioso, R. K. Meentemeyer, and D. M. Rizzo. 2018. Novel disturbance interactions between fire and an emerging disease impact survival 
and growth of resprouting trees. Ecology 99:2217-2229.

1303 Sousa, W. P. 1984. The role of disturbance in natural communities. Annual Review of $1304 \quad$ Ecology and Systematics 15:353-391.

1305 Tappeiner, J., D. Maguire, T. B. Harrington, and J. D. Bailey. 2015. Silviculture and 1306 ecology of western U.S. forests. 2nd edition. Oregon State University Press, Corvallis, 1307 Oregon, USA.

1308 Thorne, J. H., H. Choe, R. M. Boynton, J. Bjorkman, W. Albright, K. Nydick, A. L. Flint, L.

1309 E. Flint, and M. W. Schwartz. 2017. The impact of climate change uncertainty on $1310 \quad$ California's vegetation and adaptation management. Ecosphere 8.

1311 Thorne, J. H., H. Choe, P. A. Stine, J. C. Chambers, A. Holguin, A. C. Kerr, and M. W.

1312 Schwartz. 2018. Climate change vulnerability assessment of forests in the Southwest

$1313 \quad$ USA. Climatic Change 148:387-402.

1314 Trauernicht, C., B. W. Brook, B. P. Murphy, G. J. Williamson, and D. M. J. S. Bowman.

1315 2015. Local and global pyrogeographic evidence that indigenous fire management $1316 \quad$ creates pyrodiversity. Ecology and Evolution 5:1908-1918.

1317 Trumbore, S., P. Brando, and H. Hartmann. 2015. Forest health and global change. Science $1318 \quad 349: 814-818$.

1319 Turner, M. G. 2010. Disturbance and landscape dynamics in a changing world. Ecology $1320 \quad 91: 2833-2849$.

1321 Turner, M. G., and R. H. Gardner. 2015. Landscape ecology in theory and practice: pattern 1322 and process. 2nd edition. Springer-Verlag, New York, New York, USA.

1323 Vicuna, S., and J. A. Dracup. 2007. The evolution of climate change impact studies on 1324 hydrology and water resources in California. Climatic Change 82:327-350.

1325 Vogelmann, J. E., S. Howard, M. G. Rollins, J. R. Kost, B. Tolk, K. Short, X. Chen, K. Pabst, 1326 and C. Huang. 2011. Monitoring landscape change for LANDFIRE using multi- 
temporal satellite imagery and ancillary data. IEEE Journal of Selected Topics in

$1328 \quad$ Applied Earth Observations and Remote Sensing 4:252-264.

1329 Vogelmann, J. E., B. Tolk, and Z. Zhu. 2009. Monitoring forest changes in the southwestern

1330 United States using multitemporal Landsat data. Remote Sensing of Environment

$1331 \quad 113: 1739-1748$.

1332 Vogelmann, J. E., G. Xian, C. Homer, and B. Tolk. 2012. Monitoring gradual ecosystem

1333 change using Landsat time series analyses: case studies in selected forest and

1334 rangeland ecosystems. Remote Sensing of Environment 122:92-105.

1335 Wear, J. F., R. B. Pope, and P. W. Orr. 1966. Aerial photographic techniques for estimating

1336 damage by insects in western forests. U.S. Department of Agriculture, Forest Service,

1337 Pacific Northwest Forest and Range Experiment Station. Portland, Oregon, USA.

1338 Wood, E. M., A. M. Pidgeon, V. C. Radeloff, and N. S. Keuler. 2012. Image texture as a

1339 remotely sensed measure of vegetation structure. Remote Sensing of Environment

$1340 \quad 121: 516-526$.

1341 Wu, G., K. Guan, C. Jiang, B. Peng, H. Kimm, M. Chen, X. Yang, S. Wang, A. E. Sukyer, C.

1342 Bernacchi, C. E. Moore, Y. Zeng, J. Berry, and M. P. Cendrero-Mateo. 2020. Radiance-

1343 based NIRv as a proxy for GPP of corn and soybean. Environmental Research Letters

$1344 \quad 15: 034009$.

1345 Zwanenburg, A., S. Leger, M. Vallières, and S. Löck. 2016. Image biomarker

1346 standardisation initiative. ArXiv:1612.07003. 
bioRxiv preprint doi: https://doi.org/10.1101/2020.1123.394221: this version posted November 23,2020 . The copyright holder for this preprint (which was not certified by peer review) is the author/funder, who has granted bioRxiv a license to display the preprint in perpetuity. It is made available under aCC-BY-NC-ND 4.0 International license.

1348 Table 1. Recent temporal segmentation procedures for discriminating abrupt and trend 1349 vegetation change using remotely sensed data.

1350

\begin{tabular}{llcl}
\hline Acronym & Name & Year & Citation \\
\hline BFAST & Breaks for Additive and Seasonal Trend & 2010 & Verbesselt et al. 2010 \\
LandTrendr & $\begin{array}{l}\text { Landsat-based Detection of Trends in } \\
\text { Disturbance and Recovery }\end{array}$ & 2010 & Kennedy et al. 2010 \\
DBEST & $\begin{array}{l}\text { Detecting Breakpoints and Estimating } \\
\text { Segments in Trend }\end{array}$ & 2015 & Jamali et al. 2015 \\
MTHD & Multi-Target Hierarchical Detection & 2016 & Xu et al. 2016 \\
\hline
\end{tabular}


bioRxiv preprint doi: https://doi.org/10.1101/2020.1123.394221: this version posted November 23,2020 . The copyright holder for this preprint (which was not certified by peer review) is the author/funder, who has granted bioRxiv a license to display the preprint in perpetuity. It is made available under aCC-BY-NC-ND 4.0 International license.

1352 Table 2. The three vegetation indices applied in the temporal segmentation procedure, 1353 with their respective calculations and Landsat 7 Thematic Mapper (TM) band inputs.

1354

\begin{tabular}{lll}
\hline Index & Calculation & $\begin{array}{l}\text { Landsat 7 TM } \\
\text { Bands }\end{array}$ \\
\hline NDVI & $\frac{\mathrm{NIR}-\mathrm{Red}}{\mathrm{NIR}+\mathrm{Red}}$ & $\frac{\mathrm{B} 4-\mathrm{B} 3}{\mathrm{~B} 4+\mathrm{B} 3}$ \\
$\mathrm{NBR}$ & $\frac{\mathrm{NIR}-\mathrm{SWIR}}{\mathrm{NIR}+\mathrm{SWIR}}$ & $\frac{\mathrm{B} 4-\mathrm{B} 7}{\mathrm{~B} 4+\mathrm{B} 7}$ \\
NIR $_{\mathrm{V}}$ & $\frac{\mathrm{NIR}-\mathrm{Red}}{\mathrm{NIR}+\mathrm{Red}} \times \mathrm{NIR}$ & $\frac{\mathrm{B} 4-\mathrm{B} 3}{\mathrm{~B} 4+\mathrm{B} 3} \times \mathrm{B} 4$
\end{tabular}

1355 
1356 Table 3. Definitions of pixel trajectory metrics: year of detection, magnitude, disturbance signal-to-noise ratio, duration, and rate. Metrics were derived through temporal

1358 segmentation of vegetation index time series.

1359

Metric Definition

Year of detection

Magnitude

Disturbance signal-to-noise ratio

Duration

Rate of change
Year in which a directional change (vertex) occurred

Value of change in spectral response

Magnitude normalized to the root mean squared error (RMSE) of the LandTrendr fit

Horizontal length of the segment

Magnitude / Duration 
1361 Table 4. Three theoretically independent metrics for quantifying textural characteristics in 1362 forest remote sensing applications.

1363

\begin{tabular}{lll}
\hline Metric & \multicolumn{1}{c}{ Equation } & Description \\
Contrast & $\sum_{i, j}^{N} p(i, j)|i-j|^{2}$ & $\begin{array}{l}\text { Sum of squares of variance in grey-level } \\
\text { values between adjacent pixels. }\end{array}$ \\
Correlation & $\sum_{i, j}^{N} \frac{(i-\mu i)(j-\mu j) p(i, j)}{\sigma_{i} \sigma_{j}}$ & $\begin{array}{l}\text { Linear dependence of grey-level values on } \\
\text { those of neighboring pixels. }\end{array}$ \\
Entropy & $\sum_{i, j=0}^{N-1}-\ln (p(i, j)) p(i, j)$ & $\begin{array}{l}\text { Natural log of the probability of co- } \\
\text { occurrence of equal grey-level values. }\end{array}$ \\
\hline
\end{tabular}


bioRxiv preprint doi: https://doi.org/10.1101/2020.11.23.394221; this version posted November 23, 2020. The copyright holder for this preprint (which was not certified by peer review) is the author/funder, who has granted bioRxiv a license to display the preprint in perpetuity. It is made available under aCC-BY-NC-ND 4.0 International license.

1365 Table 5. Pearson's correlation coefficients for selected GLCM texture metrics.

\begin{tabular}{cc}
\hline Variable Pair & Pearson's $r$ \\
\hline con-cor & $0.1397^{* * *}$ \\
con-ent & $0.0185^{* * *}$ \\
cor-ent & $0.0869^{* * *}$ \\
\hline \multirow{2}{*}{$* * * \mathrm{p}<0.01$}
\end{tabular}


bioRxiv preprint doi: https://doi.org/10.1101/2020.11.23.394221: this version posted November 23, 2020. The copyright holder for this preprint (which was not certified by peer review) is the author/funder, who has granted bioRxiv a license to display the preprint in perpetuity. It is made available under aCC-BY-NC-ND 4.0 International license.

1367 Table 6. Disturbance detection accuracy and Cohen's Kappa ( $k$ when NBR, NDVI, and 1368 NIRv were assimilated separately in the temporal segmentation procedure.

1369

1370

\begin{tabular}{lrr}
\hline Index & Accuracy & $\boldsymbol{\kappa}$ \\
\hline NBR & $70.4 \%$ & 0.537 \\
NDVI & $74.2 \%$ & 0.598 \\
NIRV & $69.3 \%$ & 0.527 \\
\hline
\end{tabular}


Table 7. Error matrices for RF classification models: (a) Model 1 (texture metrics excluded) and (b) Model 2 (texture metrics included). Within the shaded box, numbers in cells represent the count of sample pixels in each category. Column values represent observations in the reference data and all sum to 200 pixels per class. Row values represent modeled agent predictions and sum to total predictions for that class. Diagonal (darker) cells contain correct identifications; off-diagonal (lighter) cells contain errors. Row and column totals, omission errors (OE), and commission errors (CE) appear in italics. Commission error is calculated as the sum of false-positive predictions (row errors) over total predictions per class. Omission error is calculated as the sum of false-negative predictions (column errors) over total reference points per class. The proportion of pixels correctly classified (PCC) appears in the bottom-right cell of each matrix.

\section{(a) Model 1: GLCM texture variables excluded}

\begin{tabular}{|c|c|c|c|c|c|c|c|c|}
\hline & \multicolumn{5}{|c|}{ Reference } & \multirow[b]{2}{*}{ Total } & \multirow[b]{2}{*}{$C E$} \\
\hline & & Fire & Harvest & Stress & $\begin{array}{l}\text { Stable } \\
\text { forest }\end{array}$ & $\begin{array}{l}\text { Stable } \\
\text { non- } \\
\text { forest }\end{array}$ & & \\
\hline \multirow{7}{*}{ 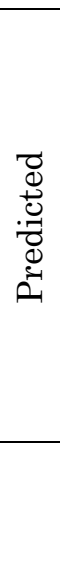 } & Fire & 111 & 31 & 12 & 13 & $\overline{0}$ & 167 & 0.335 \\
\hline & Harvest & 36 & 105 & 4 & 56 & 0 & 201 & 0.478 \\
\hline & Stress & 31 & 4 & 178 & 5 & 0 & 218 & 0.183 \\
\hline & Stable forest & 22 & 60 & 6 & 126 & 0 & 214 & 0.411 \\
\hline & Stable non-forest & 0 & 0 & 0 & 0 & 200 & 200 & 0.000 \\
\hline & Total & 200 & 200 & 200 & 200 & 200 & 1000 & $P C C$ \\
\hline & $O E$ & 0.445 & 0.475 & 0.110 & 0.370 & 0.000 & $P C C$ & 0.720 \\
\hline
\end{tabular}


bioRxiv preprint doi: https://doi.org/10.1101/2020.1123.394221. this version posted November 23, 2020. The copyright holder for this preprint (which was not certified by peer review) is the author/funder, who has granted bioRxiv a license to display the preprint in perpetuity. It is made available under aCC-BY-NC-ND 4.0 International license.

(b) Model 2: texture variables included

\begin{tabular}{|c|c|c|c|c|c|c|c|c|}
\hline & \multicolumn{5}{|c|}{ Reference } & \multirow[b]{2}{*}{ Total } & \multirow[b]{2}{*}{$C E$} \\
\hline & & Fire & Harvest & Stress & $\begin{array}{l}\text { Stable } \\
\text { forest }\end{array}$ & $\begin{array}{l}\text { Stable } \\
\text { non- } \\
\text { forest }\end{array}$ & & \\
\hline \multirow{7}{*}{ 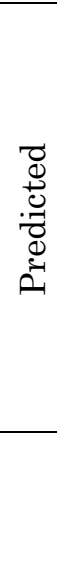 } & Fire & 110 & 28 & 10 & 14 & 0 & 162 & 0.321 \\
\hline & Harvest & 36 & 120 & 7 & 70 & 0 & 233 & 0.485 \\
\hline & Stress & 35 & 5 & 179 & 3 & 0 & 222 & 0.194 \\
\hline & Stable forest & 19 & 47 & 4 & 113 & 0 & 183 & 0.383 \\
\hline & Stable non-forest & 0 & 0 & 0 & 0 & 200 & 200 & 0.000 \\
\hline & Total & 200 & 200 & 200 & 200 & 200 & 1000 & $P C C$ \\
\hline & $O E$ & 0.450 & 0.400 & 0.105 & 0.435 & 0.000 & $P C C$ & 0.722 \\
\hline
\end{tabular}


1389 Table 8. Relative importance of the top 15 predictor variables in Model 1 (textures

1390 excluded) and Model 2 (textures included). Importance is expressed in terms of mean

1391 decrease in accuracy (MDA), the accuracy penalty that would result if a variable were

1392 excluded from the set of predictors. Texture variables that appeared in the top 15 for Model

13932 are in bold type.

1394

Model 1: texture metrics excluded

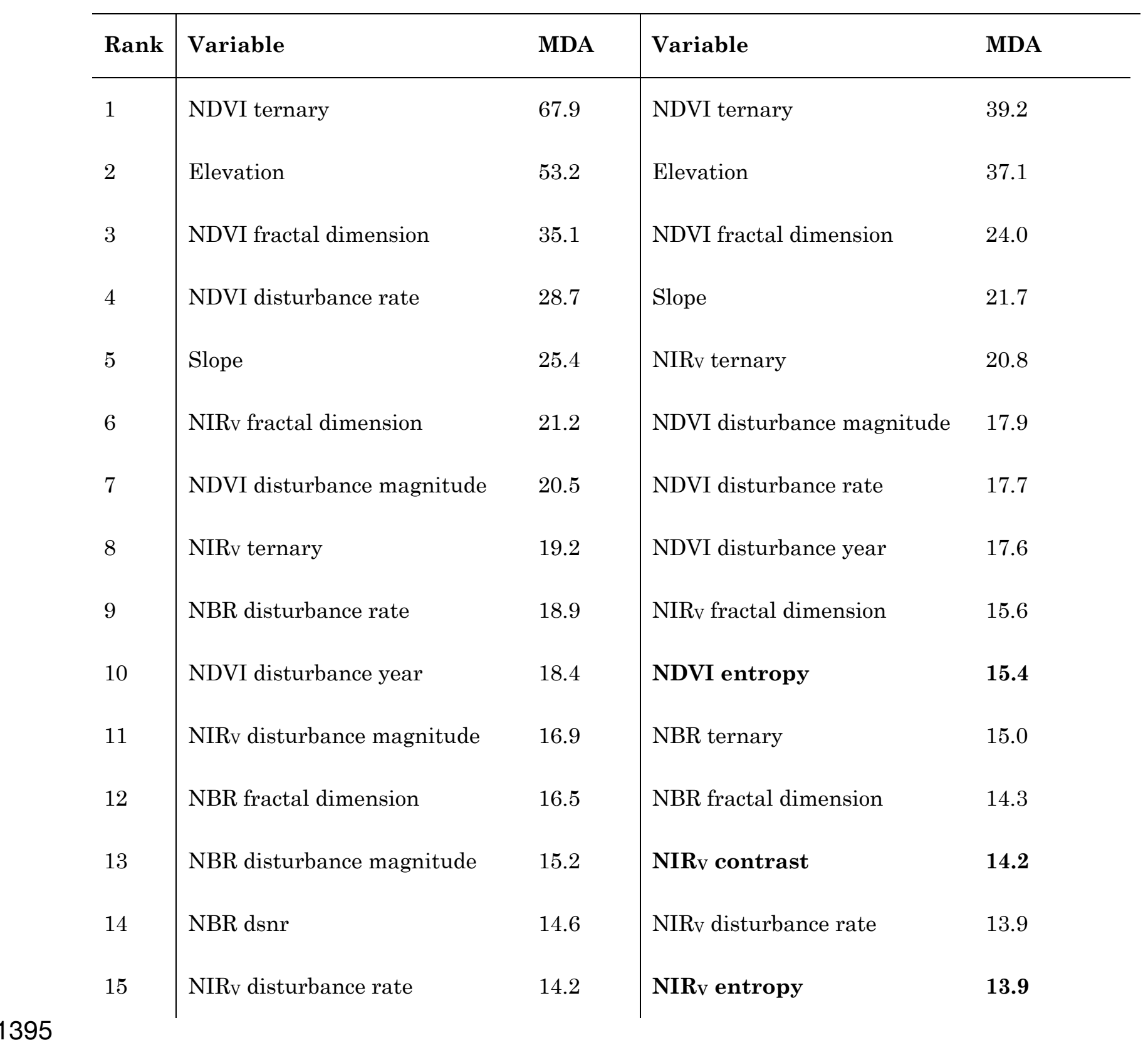

Model 2: texture metrics included 


\section{Figure Legends}

Figure 1. Photographs of Sierra Nevada mixed-conifer forest sites disturbed by (a) mixed-

1399 severity fire, (b) bark beetles, and (c) harvest. Each photograph was made within one year

1400 of disturbance and reveals a distinctive structural legacy.

1402 Figure 2. True-color composite image of Stanislaus National Forest in July 2014

1403 (California, U.S.A., inset). The composite was created from bands $2-4$ of a Landsat 8

1404 Enhanced Thematic Mapper (ETM+) image made approximately eleven months after the

1405 Rim Fire began. The fire scar is visible across the image's lower third. Extensive harvest

1406 patches ( 16 hectares each) appear in the speckled regions to the north and west. Surface

1407 water and cloud shadows are masked and appear white.

1408

1409 Figure 3. A flowchart of the data processing methods detailed in this study. Steps 1-3

1410 pertain to $§ 2.2 .2$. Step 4 is described in $\S 2.2 .3$. Steps $5-8$ are detailed in $\S 2.2 .4$ and $\S 2.2 .5$.

1411 Step 9 is described in $§ 2.3$, and Step 10 in $§ 2.4$.

1413 Figure 4. NIRv and best-fit spectral trajectories of randomly selected pixels in three

1414 possible trajectory groups: "Disturbed", "Stable Forest", and "Stable Non-Forest." Red lines

1415 indicate spectral trajectory based on observed NIR $_{V}$ values. Blue lines represent the model

1416 that best simplified the trajectory shape based on thresholds defined in the temporal

1417 segmentation procedure.

1418

1419 Figure 5. Graphical representations of the correlation coefficient Pearson's $r$ calculated for 1420 pairs of GLCM texture metrics for 1999-2015 vegetation index values. Blue values indicate 
1421 positive correlation; red, negative correlation. Ellipse width and color saturation indicate

1422 the strength of the relationship. Here, the metrics contrast (con), correlation (cor), and

1423 entropy (ent) were selected for inclusion as robust independent measures of edge, interior

1424 structure, and interior randomness, respectively. Names and variable definitions for the

1425 predictor codes are in Appendix A.

1426

1427 Figure 6. A true-color composite (a) shown alongside three GLCM texture metrics for a 25

$1428 \mathrm{~km}^{2}$ subset of the study domain. Contrast (b), correlation (c), and entropy (d) were

1429 calculated on $\mathrm{NIR}_{\mathrm{V}}$ returns for 2014. The approximate location of the subset area within the

1430 Stanislaus National Forest boundary appears in the centered map.

1431

1432 Figure 7. Pixels identified as disturbed as a proportion of total within Stanislaus National

1433 Forest boundaries. Disturbance was detected through a temporal segmentation procedure

1434 run on time-series stacks of NBR, NDVI, and NIR v values, which were computed on annual

1435 composites of Landsat observations from 1999-2015.

1436

1437 Figure 8. Magnitude of greatest disturbance events shown in histograms (a-c) and mapped

1438 at 30-m pixel scale (d-f) within the Stanislaus National Forest boundary. Disturbance

1439 location and magnitude were identified by temporal segmentation of NDVI, NIR , and NBR

1440 time-series.

1441

1442 Figure 9. Mapped predictions of disturbance agents: (a) Model 1 (texture metrics excluded)

1443 and (b) Model 2 (texture metrics included). 
1445 Figure 10. Proportion of pixels in modeled results by predicted disturbance agent or stable

1446 status.

1448 Figure 11. Violin plots depict elevational regulation of different disturbance agents and

1449 forest cover. "Wider" oblongs indicate more peaked distributions in one or more elevational

1450 bands, while "taller" oblongs indicate a more uniform distribution along the elevational

1451 gradient. Fire and stress appear to co-occur at lower elevations, while harvest is

1452 concentrated in mid-elevations. The white boxes in the centers of the oblongs depict the

1453 median and interquartile range of elevation.

1454 
bioRxiv preprint doi: https://doi.org/10.1101/2020.11.23.394221; this version posted November 23, 2020. The copyright holder for this preprint (which was not certified by peer review) is the author/funder, who has granted bioRxiv a license to display the preprint in perpetuity. It is made available under aCC-BY-NC-ND 4.0 International license.

\section{Figure 1.}

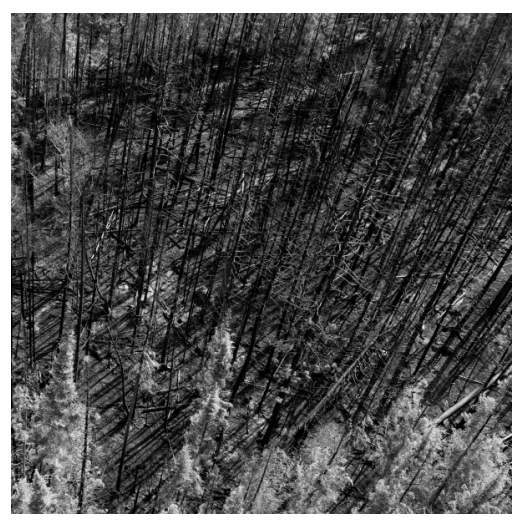

(a)

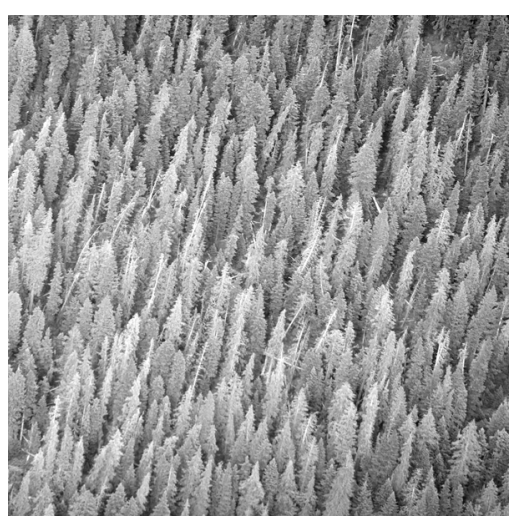

(b)

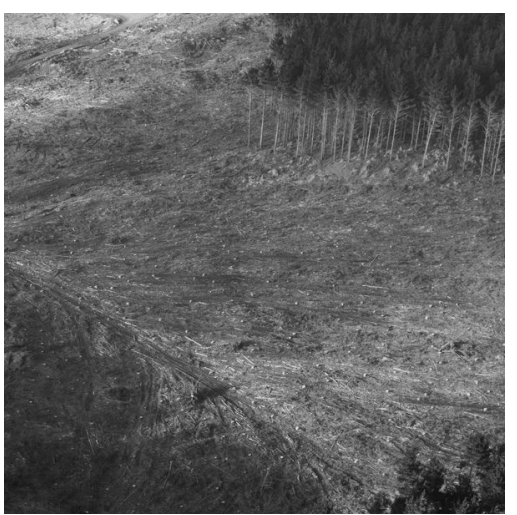

(c)

1456 
bioRxiv preprint doi: https://doi.org/10.1101/2020.11.23.394221; this version posted November 23, 2020. The copyright holder for this preprint (which was not certified by peer review) is the author/funder, who has granted bioRxiv a license to display the preprint in perpetuity. It is made available under aCC-BY-NC-ND 4.0 International license.

\section{Figure 2.}

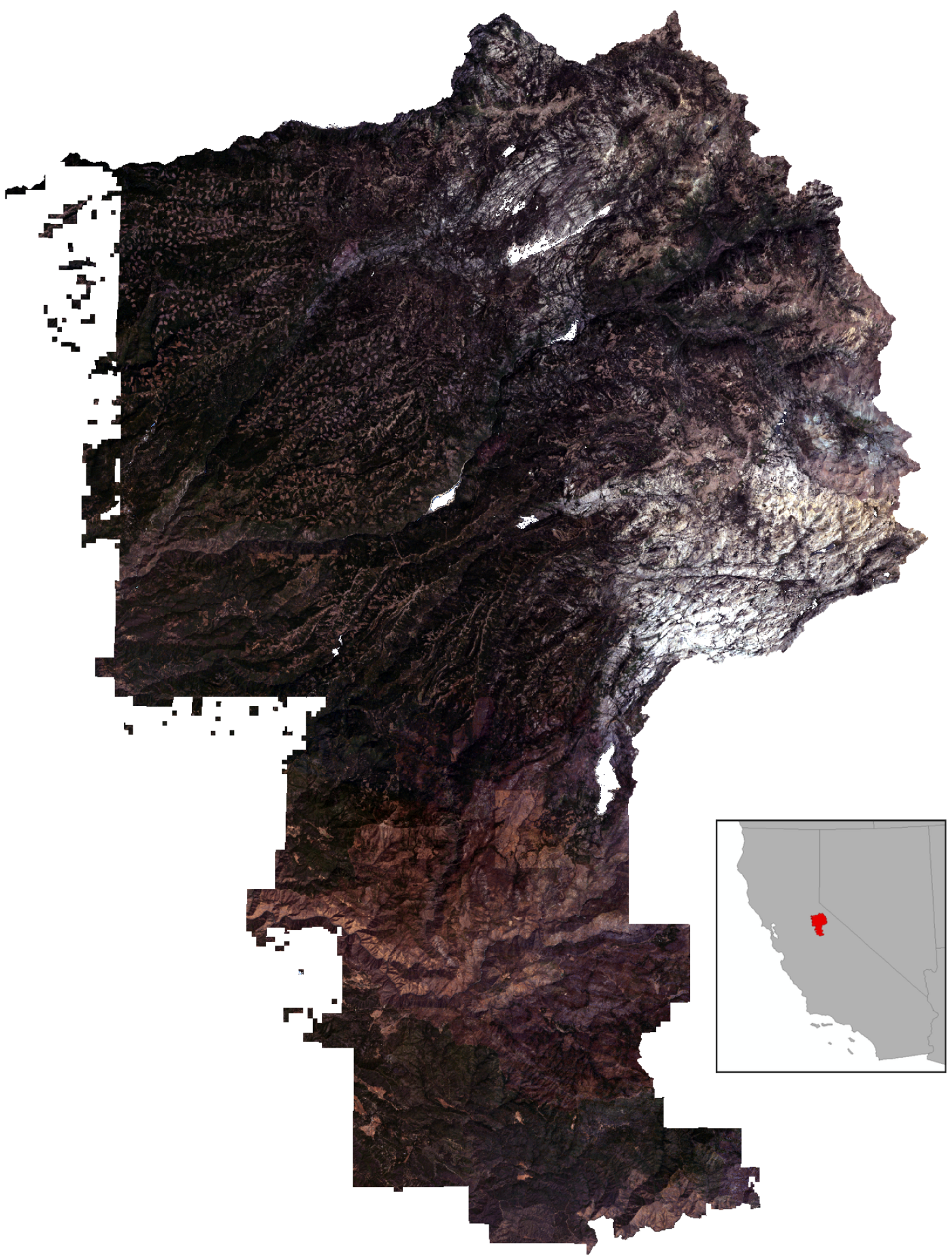


bioRxiv preprint doi: https://doi.org/10.1101/2020.11.23.394221; this version posted November 23, 2020. The copyright holder for this preprint (which was not certified by peer review) is the author/funder, who has granted bioRxiv a license to display the preprint in perpetuity. It is made available under aCC-BY-NC-ND 4.0 International license.

\section{Figure 3.}

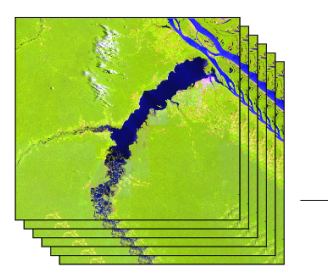

1. Landsat Stack $1999-2015$
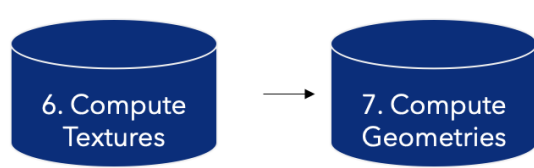

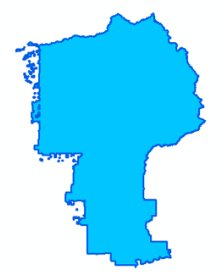

8. Constrain to NF bounds

\section{Preprocess}

Geometries 
bioRxiv preprint doi: https://doi.org/10.1101/2020.1123.394221: this version posted November 23, 2020. The copyright holder for this preprint (which was not certified by peer review) is the author/funder, who has granted bioRxiv a license to display the preprint in perpetuity. It is made available under aCC-BY-NC-ND 4.0 International license.

\section{Figure 4.}

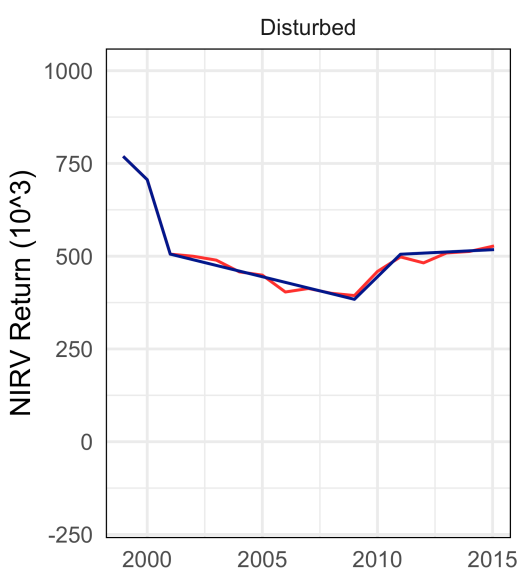

1464

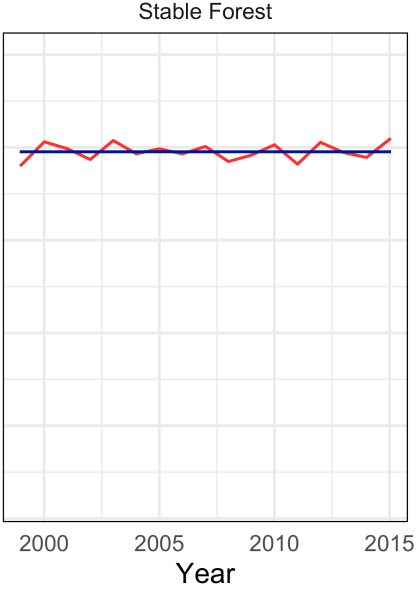

- Original values - Fitted values

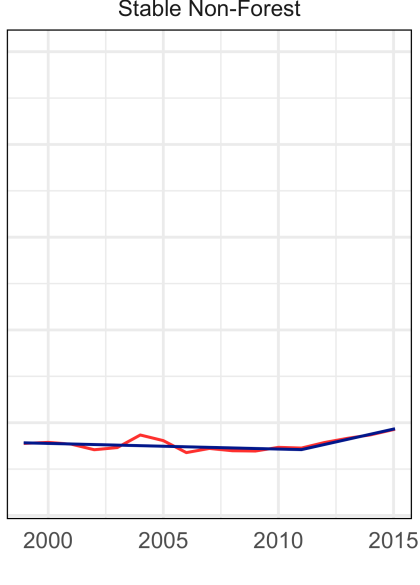

1465 
bioRxiv preprint doi: https://doi.org/10.1101/2020.11.23.394221; this version posted November 23, 2020. The copyright holder for this preprint (which was not certified by peer review) is the author/funder, who has granted bioRxiv a license to display the preprint in perpetuity. It is made available under aCC-BY-NC-ND 4.0 International license.

Figure 5.

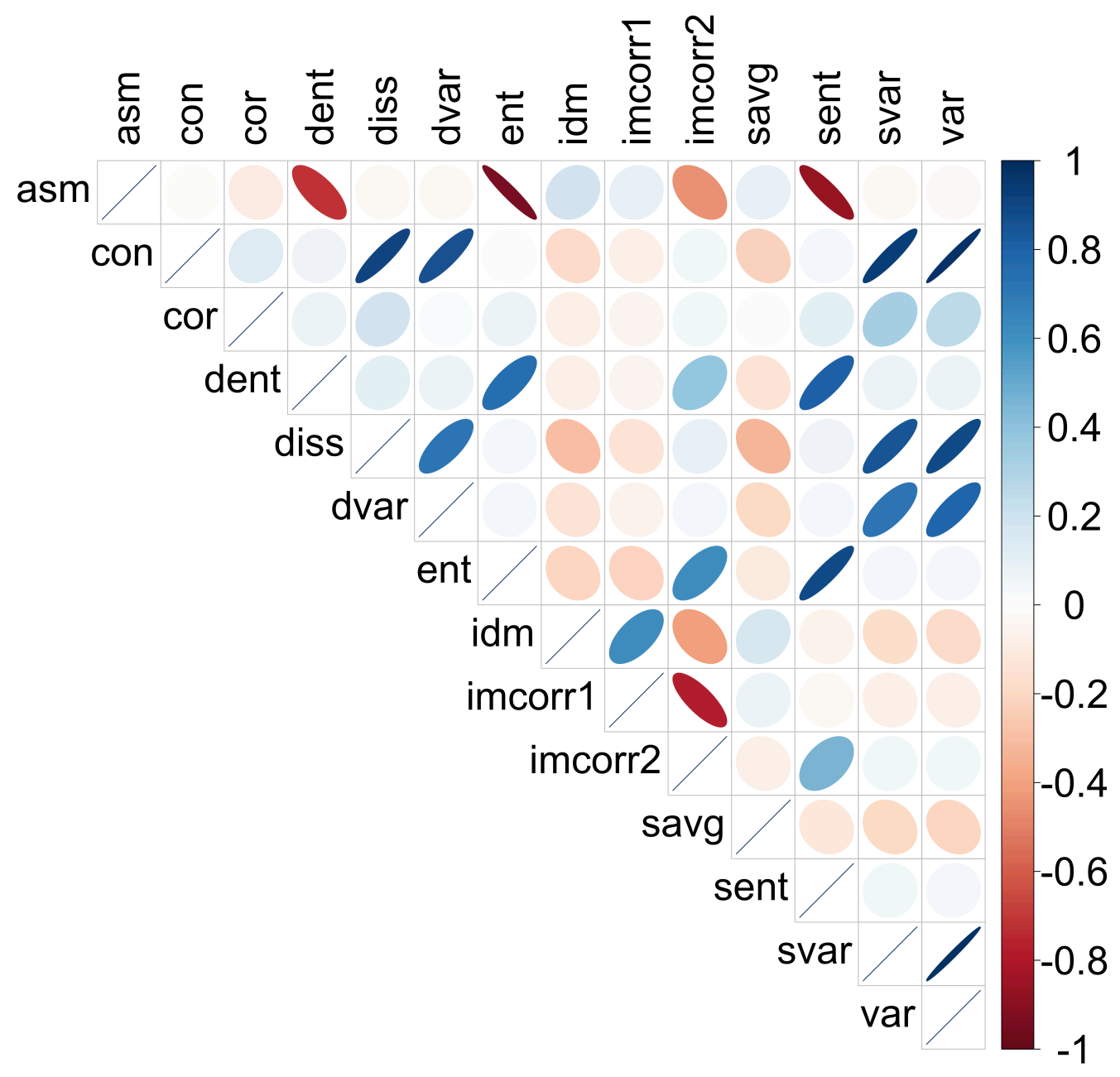


bioRxiv preprint doi: https://doi.org/10.1101/2020.11.23.394221; this version posted November 23, 2020. The copyright holder for this preprint (which was not certified by peer review) is the author/funder, who has granted bioRxiv a license to display the preprint in perpetuity. It is made available under aCC-BY-NC-ND 4.0 International license.

\section{Figure 6.}

(a)

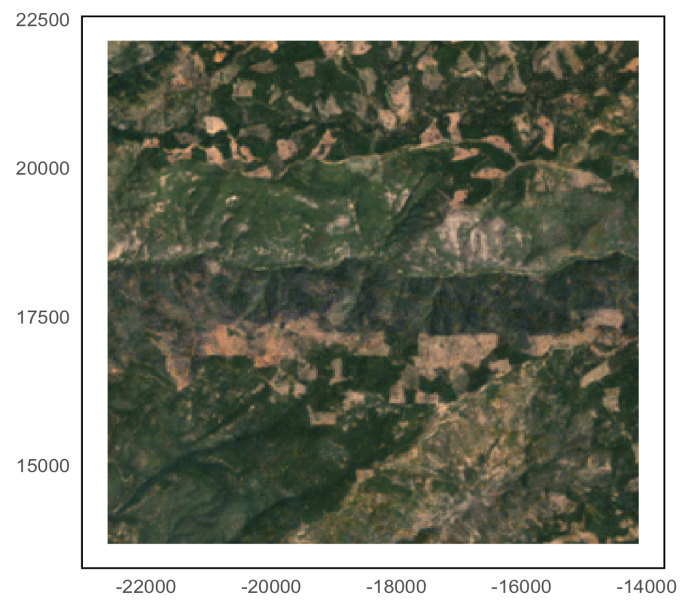

(c)

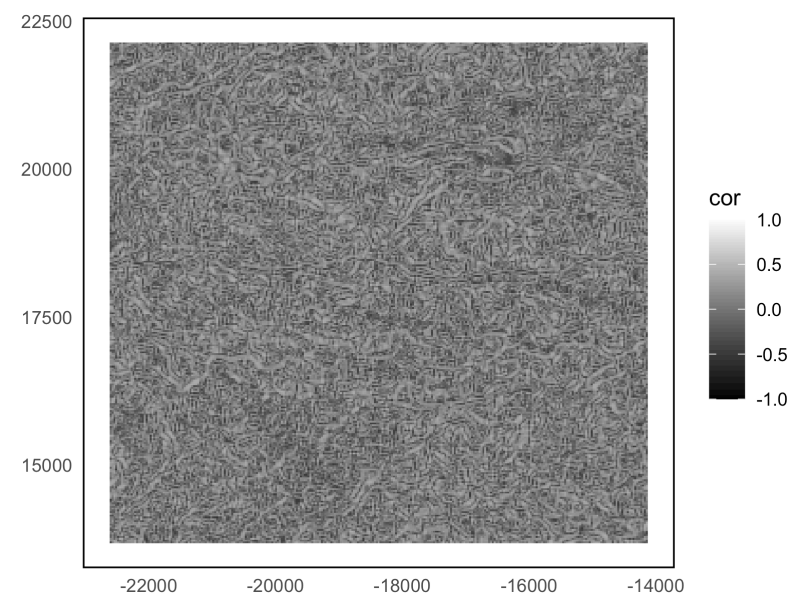

(b)

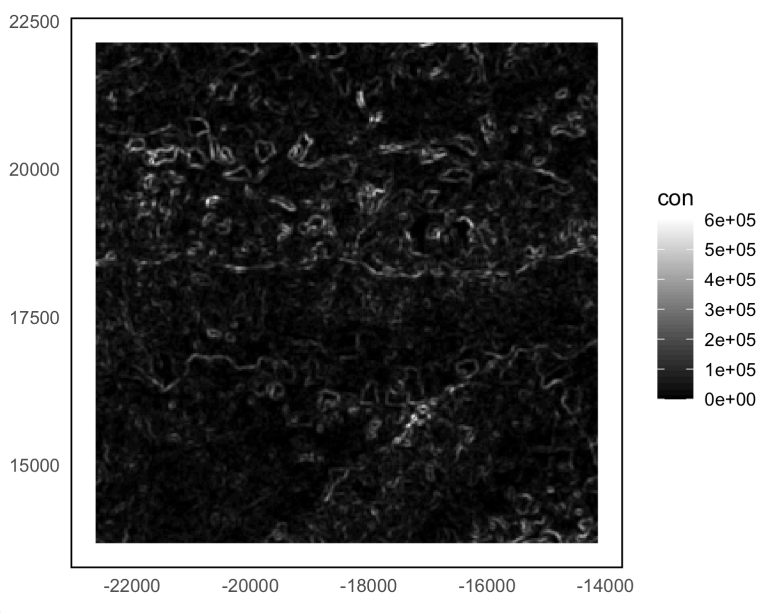

(d)




bioRxiv preprint doi: https://doi.org/10.1101/2020.11.23 394221: this version posted November 23, 2020. The copyright holder for this preprint (which was not certified by peer review) is the author/funder, who has granted bioRxiv a license to display the preprint in perpetuity. It is made available under aCC-BY-NC-ND 4.0 International license.

\section{$1470 \quad$ Figure 7.}



1471 
bioRxiv preprint doi: https://doi.org/10.1101/2020.11.23.394221; this version posted November 23, 2020. The copyright holder for this preprint (which was not certified by peer review) is the author/funder, who has granted bioRxiv a license to display the preprint in perpetuity. It is made available under aCC-BY-NC-ND 4.0 International license.

\section{$1472 \quad$ Figure 8.}

(a)

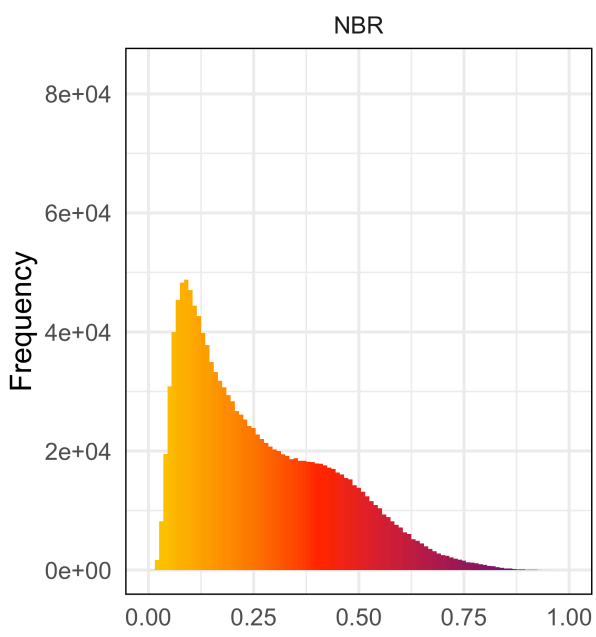

1473

(d)

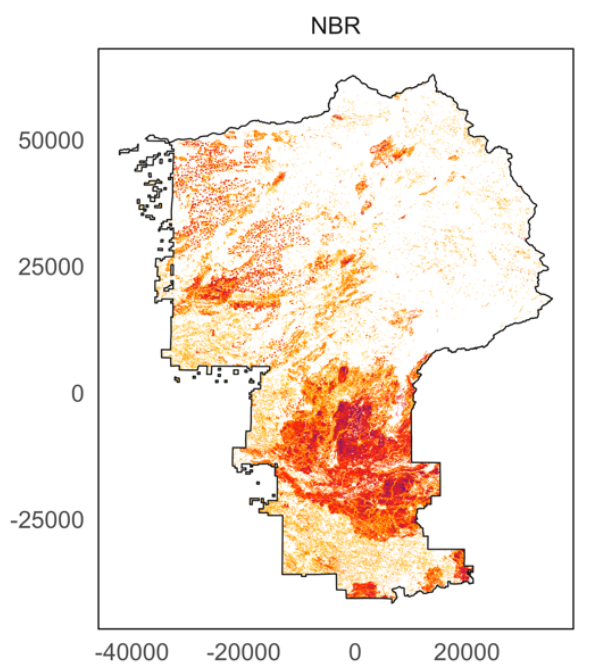

(b)

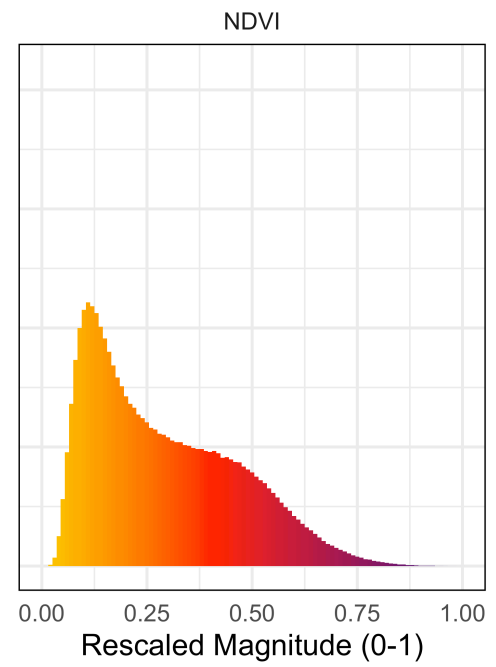

$\begin{array}{lllll}0.00 & 0.25 & 0.50 & 0.75 & 1.00\end{array}$ (c)

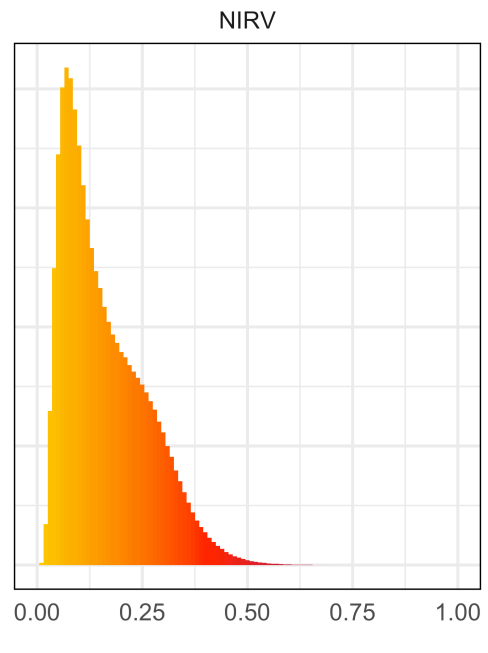

(f)


1474 
bioRxiv preprint doi: https://doi.org/10.1101/2020.11.23.394221; this version posted November 23, 2020. The copyright holder for this preprint (which was not certified by peer review) is the author/funder, who has granted bioRxiv a license to display the preprint in perpetuity. It is made available under aCC-BY-NC-ND 4.0 International license.

\section{$1475 \quad$ Figure 9.}

(a) Model 1: texture metrics excluded

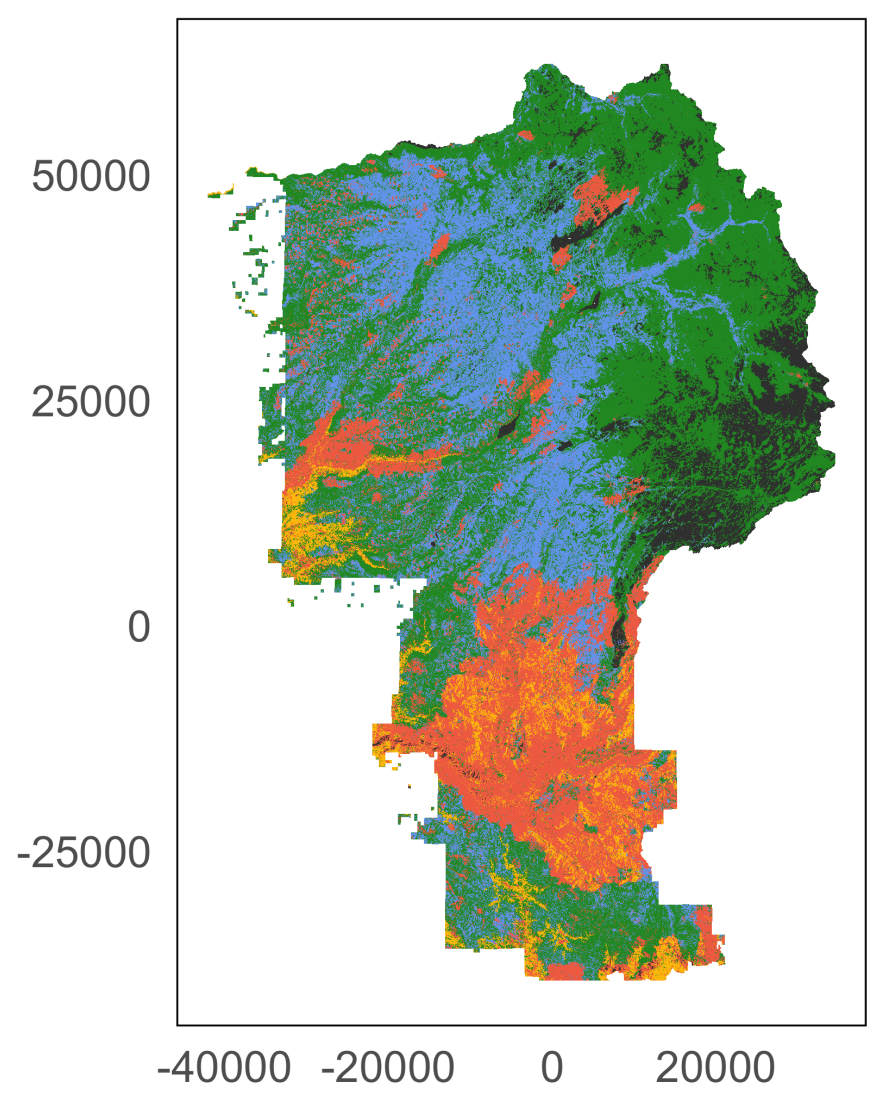

(b) Model 2: texture metrics included

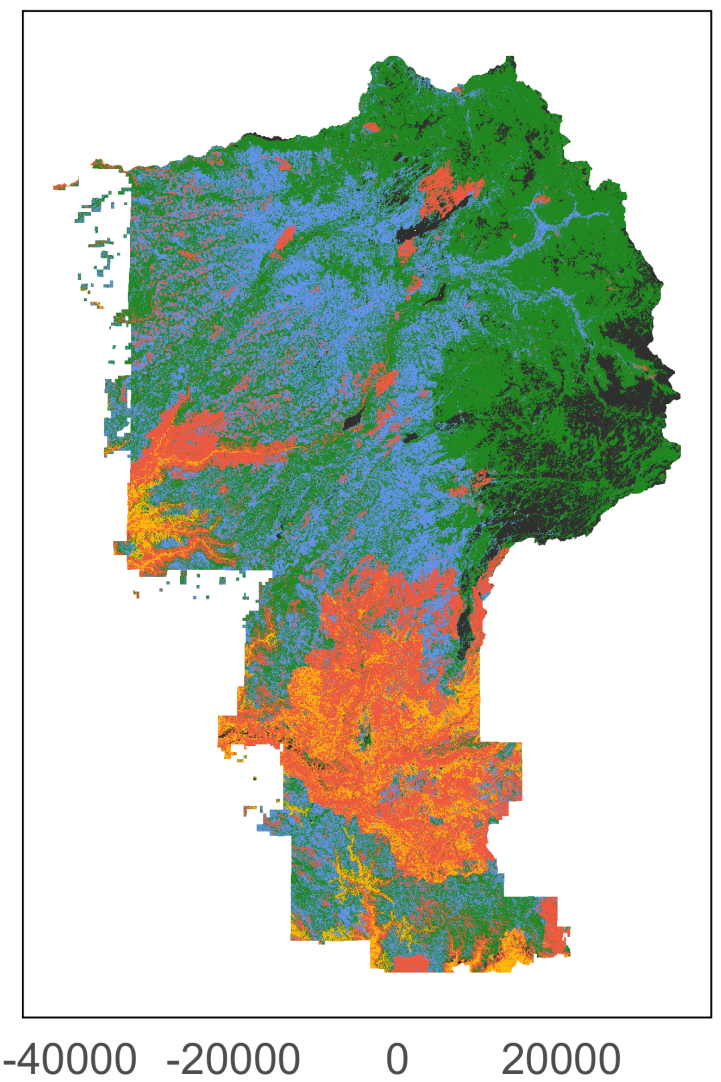


bioRxiv preprint doi: https://doi.org/10.1101/2020.11.23.394221; this version posted November 23, 2020. The copyright holder for this preprint (which was not certified by peer review) is the author/funder, who has granted bioRxiv a license to display the preprint in perpetuity. It is made available under aCC-BY-NC-ND 4.0 International license.

\section{Figure 10.}

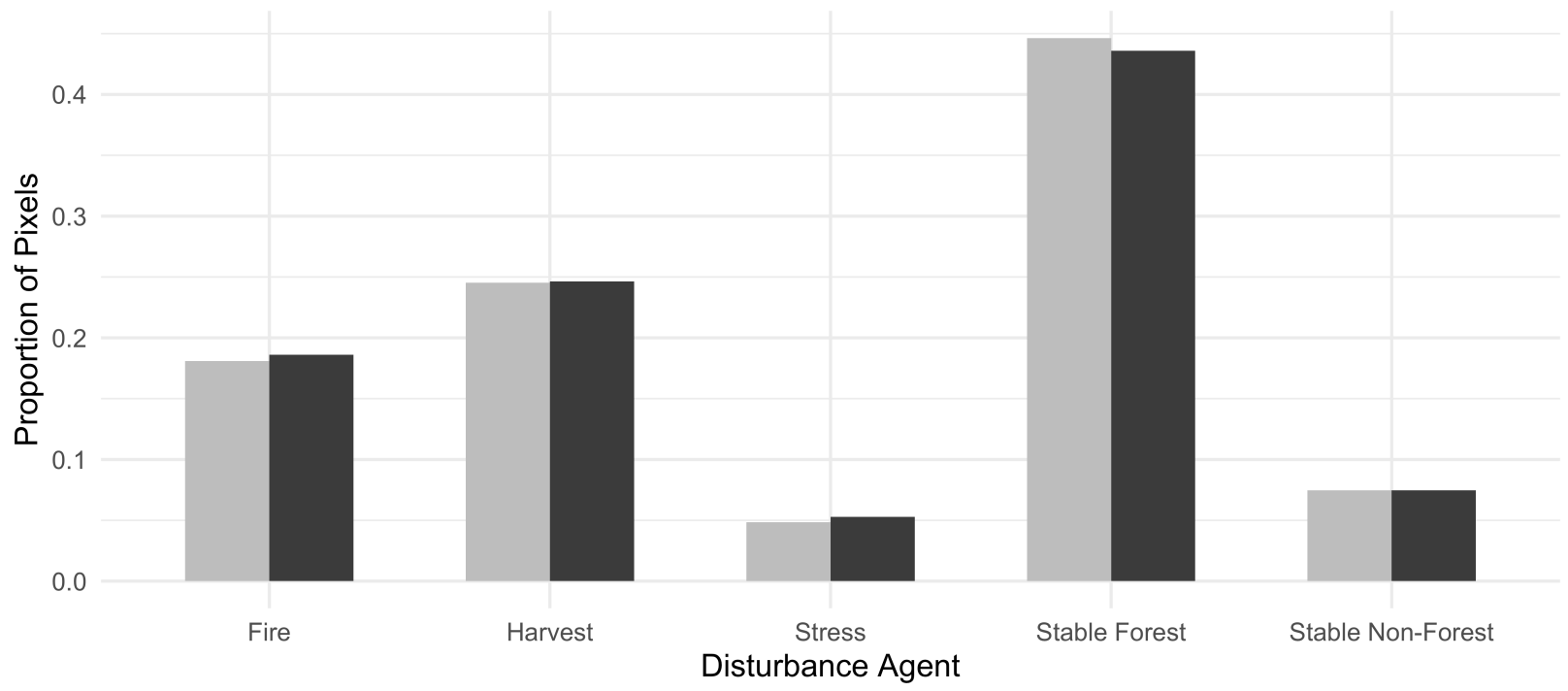


bioRxiv preprint doi: https://doi.org/10.1101/2020.11.23.394221; this version posted November 23, 2020. The copyright holder for this preprint (which was not certified by peer review) is the author/funder, who has granted bioRxiv a license to display the preprint in perpetuity. It is made available under aCC-BY-NC-ND 4.0 International license.

\section{Figure 11.}

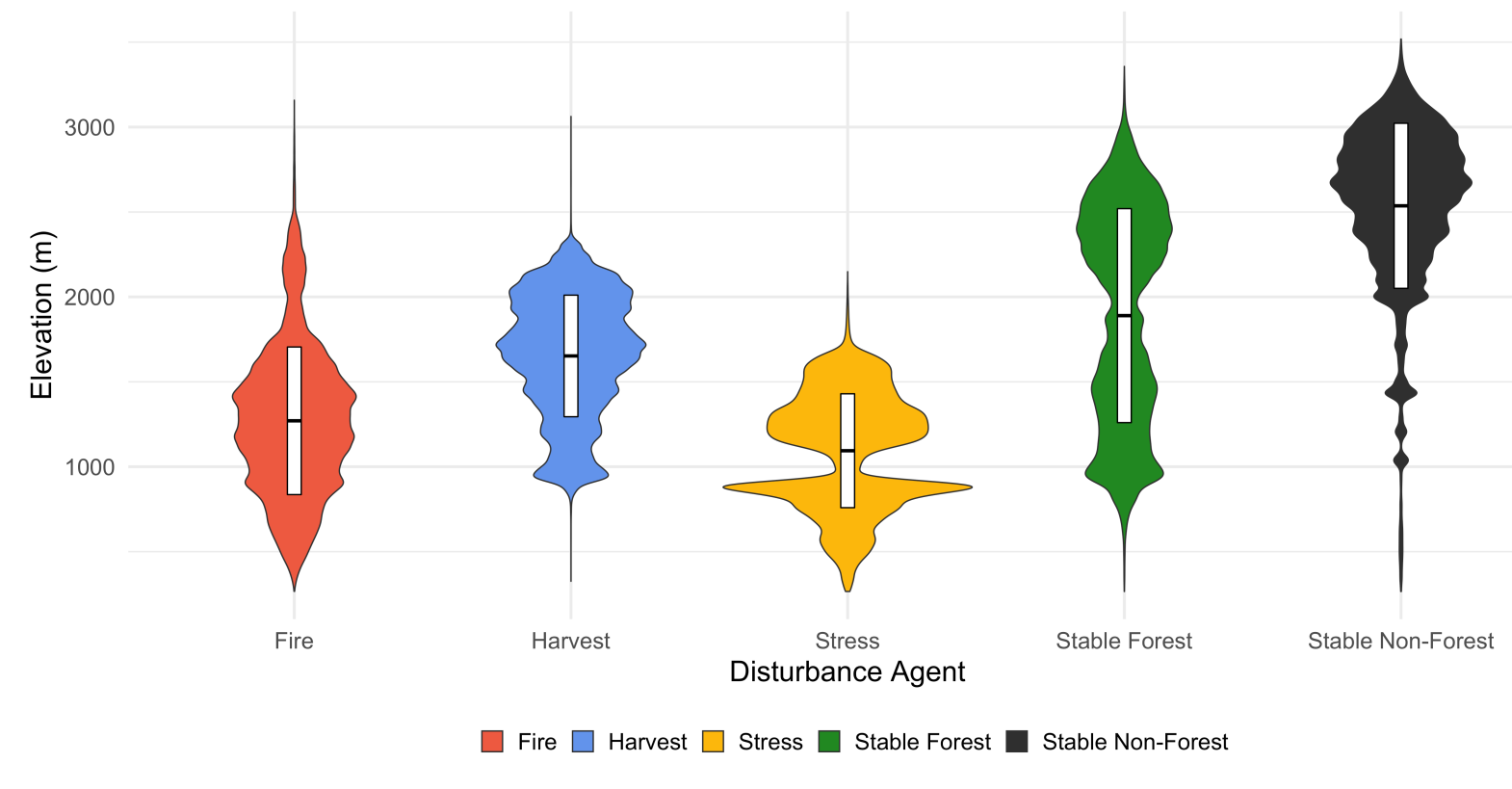


1481 Appendix A. GLCM texture variable definitions

1483 Table A. Names and definitions of the 14 GLCM texture metrics calculated on annual NDVI, NBR,

1484 and NIRV composites from 1999-2015. These metrics were tested for correlation using Pearson's $r$,

1485 and the statistics were reported in a correlation matrix (Fig. 5 in the main text). Definitions are from

1486 Zwanenburg et al. (2016), Gorelick et al. (2017), and Hall-Beyer (2017).

\begin{tabular}{|c|c|c|}
\hline Code & GLCM Variable & Measurement \\
\hline asm & Angular second moment & Number of repeated grey-level values in neighborhood \\
\hline con & Contrast & Magnitude of local differences in grey-level values \\
\hline cor & Correlation & Linear correlation between pixels in neighborhood \\
\hline dent & Difference entropy & Disorder of the distribution of grey-level differences \\
\hline diss & Dissimilarity & Mean of the distribution of grey-level differences \\
\hline dvar & Difference variance & $\begin{array}{l}\text { Dispersion (about the mean) of the distribution of grey- } \\
\text { level differences }\end{array}$ \\
\hline ent & Entropy & Randomness of grey-level distribution \\
\hline $\mathrm{idm}$ & Inverse-difference moment & Local homogeneity of an image \\
\hline imcorr 1 & Inform. meas of correlation 1 & $\begin{array}{l}\text { Linear dependency between grey-level values as a } \\
\text { function of the amount of information in the target pixel }\end{array}$ \\
\hline imcorr2 & Inform. meas. of correlation 2 & $\begin{array}{l}\text { Linear dependency between grey-level values as a } \\
\text { function of the amount of information in the test pixel }\end{array}$ \\
\hline savg & Sum average & $\begin{array}{l}\text { Mean of the distribution of neighborhood grey-level } \\
\text { sums }\end{array}$ \\
\hline sent & Sum entropy & $\begin{array}{l}\text { Disorder of the distribution of neighborhood grey-level } \\
\text { sums }\end{array}$ \\
\hline svar & Sum variance & $\begin{array}{l}\text { Dispersion (about the mean) of the distribution of } \\
\text { neighborhood grey-level sums }\end{array}$ \\
\hline var & Variance & $\begin{array}{l}\text { Dispersion (about the mean) of the distribution of grey } \\
\text { levels }\end{array}$ \\
\hline
\end{tabular}




\section{Appendix B. Model predictors}

1489 Table B.1. Predictors for Model 1: textures excluded

\begin{tabular}{|c|c|c|c|}
\hline Category & Variable & Name & Coverage \\
\hline Topographic & $\begin{array}{l}\text { Elevation } \\
\text { Cosine-transformed aspect } \\
\text { Sine-transformed aspect } \\
\text { Slope }\end{array}$ & $\begin{array}{l}\text { elevation } \\
\text { cos_aspect } \\
\text { sin_aspect } \\
\text { slope }\end{array}$ & Full domain \\
\hline Ternary & $\begin{array}{l}\text { NBR cover ternary } \\
\text { NDVI cover ternary } \\
\text { NIR } \text { cover ternary }\end{array}$ & $\begin{array}{l}\text { NBR_coverTernary } \\
\text { NDVI_coverTernary } \\
\text { NIRV_coverTernary }\end{array}$ & Full domain \\
\hline Shape & $\begin{array}{l}\text { NBR fractal dimension } \\
\text { NDVI fractal dimension } \\
\text { NIRv fractal dimension }\end{array}$ & $\begin{array}{l}\text { NBR_FracDim } \\
\text { NDVI_FracDim } \\
\text { NIRV_FracDim }\end{array}$ & Disturbed pixels \\
\hline Disturbance & $\begin{array}{l}\text { NBR disturbance magnitude } \\
\text { NBR disturbance year of detection } \\
\text { NBR disturbance signal-to-noise ratio } \\
\text { NBR disturbance rate } \\
\text { NDVI disturbance magnitude } \\
\text { NDVI disturbance year of detection } \\
\text { NDVI disturbance signal-to-noise ratio } \\
\text { NDVI disturbance rate } \\
\text { NIRV disturbance magnitude } \\
\text { NIRV disturbance year of detection } \\
\text { NIR }_{V} \text { disturbance signal-to-noise ratio } \\
\text { NIRV disturbance rate }\end{array}$ & $\begin{array}{l}\text { NBR_mag } \\
\text { NBR_yod } \\
\text { NBR_dsnr } \\
\text { NBR_rate } \\
\text { NDVI_mag } \\
\text { NDVI_yod } \\
\text { NDVI_dsnr } \\
\text { NDVI_rate } \\
\text { NIRV_mag } \\
\text { NIRV_yod } \\
\text { NIRV_dsnr } \\
\text { NIRV_rate } \\
\end{array}$ & Disturbed pixels \\
\hline
\end{tabular}


1491 Table B.2. Predictors for Model 2: textures included

\begin{tabular}{|c|c|c|c|}
\hline Category & Variable & Name & Coverage \\
\hline Topographic & $\begin{array}{l}\text { Elevation } \\
\text { Cosine-transformed aspect } \\
\text { Sine-transformed aspect } \\
\text { Slope }\end{array}$ & $\begin{array}{l}\text { elevation } \\
\text { cos_aspect } \\
\text { sin_aspect } \\
\text { slope }\end{array}$ & Full domain \\
\hline Ternary & $\begin{array}{l}\text { NBR cover ternary } \\
\text { NDVI cover ternary } \\
\text { NIRV cover ternary }\end{array}$ & $\begin{array}{l}\text { NBR_coverTernary } \\
\text { NDVI_coverTernary } \\
\text { NIRV_coverTernary }\end{array}$ & Full domain \\
\hline Shape & $\begin{array}{l}\text { NBR fractal dimension } \\
\text { NDVI fractal dimension } \\
\text { NIRV fractal dimension }\end{array}$ & $\begin{array}{l}\text { NBR_FracDim } \\
\text { NDVI_FracDim } \\
\text { NIRV_FracDim }\end{array}$ & Disturbed pixels \\
\hline Disturbance & $\begin{array}{l}\text { NBR disturbance magnitude } \\
\text { NBR disturbance year of detection } \\
\text { NBR disturbance signal-to-noise ratio } \\
\text { NBR disturbance rate } \\
\text { NDVI disturbance magnitude } \\
\text { NDVI disturbance year of detection } \\
\text { NDVI disturbance signal-to-noise ratio } \\
\text { NDVI disturbance rate } \\
\text { NIRV disturbance magnitude } \\
\text { NIRV disturbance year of detection } \\
\text { NIRV disturbance signal-to-noise ratio } \\
\text { NIRV disturbance rate }\end{array}$ & $\begin{array}{l}\text { NBR_mag } \\
\text { NBR_yod } \\
\text { NBR_dsnr } \\
\text { NBR_rate } \\
\text { NDVI_mag } \\
\text { NDVI_yod } \\
\text { NDVI_dsnr } \\
\text { NDVI_rate } \\
\text { NIRV_mag } \\
\text { NIRV_yod } \\
\text { NIRV_dsnr } \\
\text { NIRV_rate }\end{array}$ & Disturbed pixels \\
\hline Texture & $\begin{array}{l}\text { NBR contrast } \\
\text { NBR correlation } \\
\text { NBR entropy } \\
\text { NDVI contrast } \\
\text { NDVI correlation } \\
\text { NDVI entropy } \\
\text { NIRV contrast } \\
\text { NIRV correlation } \\
\text { NIR entropy }\end{array}$ & $\begin{array}{l}\text { NBR_distpx_tex_con } \\
\text { NBR_distpx_tex_cor } \\
\text { NBR_distpx_tex_ent } \\
\text { NDVI_distpx_tex_con } \\
\text { NDVI_distpx_tex_cor } \\
\text { NDVI_distpx_tex_ent } \\
\text { NIRV_distpx_tex_con } \\
\text { NIRV_distpx_tex_cor } \\
\text { NIRV_distpx_tex_ent }\end{array}$ & Disturbed pixels \\
\hline
\end{tabular}

